\title{
A conceptual framework to quantify the influence of convective boundary layer development on carbon dioxide mixing ratios
}

\author{
D. Pino ${ }^{1}$, J. Vilà-Guerau de Arellano ${ }^{2}$, W. Peters ${ }^{2}$, J. Schröter $^{2}$, C. C. van Heerwaarden ${ }^{3}$, and M. C. Krol ${ }^{2}$ \\ ${ }^{1}$ Applied Physics Department, BarcelonaTech (UPC) and Institute for Space Studies of Catalonia (IEEC-UPC), \\ Barcelona, Spain \\ ${ }^{2}$ Meteorology and Air Quality Section, Wageningen University, Wageningen, The Netherlands \\ ${ }^{3}$ Max Planck Institute for Meteorology, Hamburg, Germany \\ Correspondence to: D. Pino (david.pino@upc.edu)
}

Received: 21 October 2011 - Published in Atmos. Chem. Phys. Discuss.: 12 December 2011

Revised: 5 March 2012 - Accepted: 14 March 2012 - Published: 26 March 2012

\begin{abstract}
Interpretation of observed diurnal carbon dioxide $\left(\mathrm{CO}_{2}\right)$ mixing ratios near the surface requires knowledge of the local dynamics of the planetary boundary layer. In this paper, we study the relationship between the boundary layer dynamics and the $\mathrm{CO}_{2}$ budget in convective conditions through a newly derived set of analytical equations. From these equations, we are able to quantify how uncertainties in boundary layer dynamical variables or in the morning $\mathrm{CO}_{2}$ distribution in the mixed-layer or in the free atmosphere (FA) influence the bulk $\mathrm{CO}_{2}$ mixing ratio.

We find that the largest uncertainty incurred on the midday $\mathrm{CO}_{2}$ mixing ratio comes from the prescribed early morning $\mathrm{CO}_{2}$ mixing ratios in the stable boundary layer, and in the free atmosphere. Errors in these values influence $\mathrm{CO}_{2}$ mixing ratios inversely proportional to the boundary layer depth (h), just like uncertainties in the assumed initial boundary layer depth and surface $\mathrm{CO}_{2}$ flux. The influence of uncertainties in the boundary layer depth itself is one order of magnitude smaller. If we "invert" the problem and calculate $\mathrm{CO}_{2}$ surface exchange from observed or simulated $\mathrm{CO}_{2}$ mixing ratios, the sensitivities to errors in boundary layer dynamics also invert: they become linearly proportional to the boundary layer depth.

We demonstrate these relations for a typical well characterized situation at the Cabauw site in The Netherlands, and conclude that knowledge of the temperature and carbon dioxide profiles of the atmosphere in the early morning are of vital importance to correctly interpret observed $\mathrm{CO}_{2}$ mixing ratios during midday.
\end{abstract}

\section{Introduction}

Surface turbulent fluxes and boundary layer dynamics determine the daily evolution of temperature, moisture and other scalar quantities in the atmospheric boundary layer (Lemone et al., 2002). Focusing on the diurnal variability of $\mathrm{CO}_{2}$, some studies have improved our understanding about the influence of surface processes such as photosynthesis and respiration (Kim and Verma, 1990; Lloyd and Taylor, 1994; Jacobs and De Bruin, 1992; Baldocchi et al., 2001) but boundary layer development plays also a main role in determining the horizontal and vertical distribution of $\mathrm{CO}_{2}$ (Denning et al., 1995; Wofsy et al., 1988; Yi et al., 2004; McGrathSpangler and Denning, 2010).

Culf et al. (1997) analyzed the observations of $\mathrm{CO}_{2}$ mixing ratio and surface flux, and boundary layer depth over a tropical forest by using a mixed layer model to conclude that, in his case daytime evolution of $\mathrm{CO}_{2}$ was mainly controlled by boundary layer growth and related processes like entrainment, surface flux did not drive the $\mathrm{CO}_{2}$ mixing ratio evolution. Vilà-Guerau de Arellano et al. (2004) used aircraft and surface observations combined with mixed-layer theory to analyze the role of the entrainment of air on the distribution and evolution of carbon dioxide in the convective boundary layer (CBL), and compared the ratio of entrainment to surface $\mathrm{CO}_{2}$ fluxes with the values obtained for heat and humidity. They concluded that $\mathrm{CO}_{2}$ dilution due to entrainment of clean air from the free atmosphere during the morning is larger than the uptake at the surface. During the afternoon the process is the opposite (Desjardins et al., 1992, 1995). Casso et al. (2008), by using tall tower observations, analyzed the 
$\mathrm{CO}_{2}$ budget concluding that, even in situations when $\mathrm{CO}_{2}$ advection (Yi et al., 2000; Eugster and Siegrist, 2000; Werner et al., 2006; Sun et al., 2007; Font et al., 2010) is important, vertical turbulent transport plays a mayor role. Górska et al. (2008) extended the analysis made by Vilà-Guerau de Arellano et al. (2004) by including Large-eddy simulations (LES) over heterogeneous terrain in a new set of aircraft observation. They pointed out the importance of the entrainment flux for carbon dioxide during the late morning and early afternoon. LES was also used by Huang et al. (2011) to analyze $\mathrm{CO}_{2}$ budget in convective conditions concluding that entrainment $\mathrm{CO}_{2}$ fluxes have similar magnitude to surface fluxes and this pattern is insensitive to the weak to moderate geostrophic forcing discussed (less than $5 \mathrm{~m} \mathrm{~s}^{-1}$ ). The underestimation of the $\mathrm{CO}_{2}$ entrainment fluxes in regional models leads to a higher simulated $\mathrm{CO}_{2}$ concentration (Ter Maat et al., 2010; Dang et al., 2011).

Despite of this clear observational/modeling evidence of the importance of surface and boundary layer dynamics, a framework to quantify the uncertainties associated is still missing. Consequently, the purpose of this paper is to quantify the influence of the CBL characteristics on the daytime evolution of the $\mathrm{CO}_{2}$ mixing ratio, and the uncertainties associated to them. The investigation is further extended to determine how boundary layer dynamics influence the calculation of the inferred $\mathrm{CO}_{2}$ surface flux from the $\mathrm{CO}_{2}$ mixing ratio evolution. The study has direct consequences for analyzing the sources of error associated with boundary layer dynamics in tracer transport models (Denning et al., 1996; Bakwin et al., 2004; Williams et al., 2011).

We first derive relations between the $\mathrm{CO}_{2}$ mixing ratio evolution and the dynamics of the $\mathrm{CBL}$ and $\mathrm{CO}_{2}$ characteristics (morning values, free atmospheric gradient, surface flux). Second, based on observations taken at Cabauw (The Netherlands) a sensitivity analysis on the thermodynamic characteristics of the night-day transition (morning potential temperature inversion jump) and the free atmospheric conditions (potential temperature lapse rate) was performed. Then, we study the evolution of the $\mathrm{CO}_{2}$ mixing ratio for the different CBL analyzed.

In the first stage we derive from the $\mathrm{CO}_{2}$-budget in the boundary layer a complete set of closed analytical expressions, which represent the dependency of the evolution of the $\mathrm{CO}_{2}$ mixing ratio on three different aspects: (i) the night-day transition that controls the morning values of the boundary layer depth, and, as a consequence, of the $\mathrm{CO}_{2}$ mixing ratio; (ii) the conditions in the free atmosphere indicated by the $\mathrm{CO}_{2}$ vertical gradient; and (iii) the evolution of the boundary layer depth.

In the second stage we connect the CBL growth rate to some of its driving factors by using mixed-layer theory (Lilly, 1968; Tennekes and Driedonks, 1981). In this work different values of the morning potential temperature jump at the inversion and of the potential temperature lapse rate are considered. By so doing, we are able study the sensitiv- ity of the $\mathrm{CO}_{2}$ budget as well as the sensitivity of any of its variables to uncertainties in the initial inversion strength or lapse rate. In spite of its conceptually, mixed layer theory has been successfully used to study the impact of boundary layer dynamics on the $\mathrm{CO}_{2}$ concentration or on the atmospheric chemistry in the convective boundary layer (Culf et al., 1997; Vilà-Guerau de Arellano et al., 2004).

Moreover, by inverting the analytical expressions, the influence of uncertainties in $\mathrm{CO}_{2}$ free atmospheric or boundary layer conditions or boundary layer evolution to the surface exchange of $\mathrm{CO}_{2}$ is also analyzed.

The research objectives are summarized as follows:

1. To analytically describe the CBL dynamic factors that influences the diurnal variability of the $\mathrm{CO}_{2}$ mixing ratio.

2. To study the sensitivities of $\mathrm{CO}_{2}$ mixing ratio to errors in the determination or measurements of the boundary layer depth and $\mathrm{CO}_{2}$ mixing ratio at the boundary layer and free atmosphere.

3. By inverting the previous relationships, to perform the same analysis for the inverse calculation of $\mathrm{CO}_{2}$ surface flux.

4. To analyze how these sensitivities depend on the boundary layer characteristics.

These objectives have a number of important implications for inverse estimation of $\mathrm{CO}_{2}$ surface flux, such as done on global (Bousquet et al., 1999) and regional scales (Bakwin et al., 2004; Gerbig et al., 2008; Göckede et al., 2010; KeppelAleks et al., 2012).

Our proposed strategy is hardly ever practiced in $\mathrm{CO}_{2}$ inverse modeling because boundary layer depths are either immutable in the offline transport models used, or part of an online land-surface scheme that is decoupled from $\mathrm{CO}_{2}$ exchange and treated as "black-box". And even if CBL depths are simulated carefully, they are rarely reported or evaluated along with the estimated surface flux. Partly this results from a lack of awareness in the $\mathrm{CO}_{2}$ inverse modeling community of the importance of the dynamic variables in their estimations, but also because simple frameworks to assess this influence such as presented here were lacking thus far.

First, we find that errors in estimated surface flux depend on errors in the different variables (e.g. morning $\mathrm{CO}_{2}$ mixing ratio in the free atmosphere or in mixed layer) through the boundary layer depth in a quadratic or linear way. This suggests that it is very important to first minimize errors in the simulated CBL depth because it affects all the variables, and then to minimize errors in the individual $\mathrm{CO}_{2}$ related variables in the atmosphere, specially for the observed $\mathrm{CO}_{2}$ mixing ratio, and the simulated or observed mixing ratio in the free atmosphere.

Second, to make correct surface $\mathrm{CO}_{2}$ exchange estimates requires not only high quality in situ $\mathrm{CO}_{2}$ observations in the 
mixed-layer, but also good knowledge of other variables such as CBL depth, or early morning $\mathrm{CO}_{2}$ mixing ratio in the stable boundary layer and FA. However there is a lack of this type of observations because, for instance, only a few talltowers exist which provide information about the $\mathrm{CO}_{2}$ characteristics in the upper levels. Access to such observations could allow, first of all, to characterize the errors currently incurred in inverse $\mathrm{CO}_{2}$ estimates, but also they would help to improve the weather models that these estimates rely on with regards the large spread when it comes to simulating $\mathrm{CO}_{2}$ exchange across the entrainment zone (Stephens et al., 2007; Yang et al., 2007).

The paper is structured as follows. In the next section the theoretical framework used to derive the evolution and sensitivity of mixing ratio, and the inferred surface flux, of $\mathrm{CO}_{2}$ to the boundary layer characteristics is analytically derived (stage 1). In the third section, we select a day with very complete meteorological and $\mathrm{CO}_{2}$ measurements at the surface and in the low levels of the boundary layer and analyze how the mixed-layer model reproduces the observations. Based on this case, in Sect. 4 the analytical expressions presented in Sect. 2 are applied to a sensitivity analysis performed by the mixed-layer model based on the observations (stage 2). We end the paper by summarizing the main findings and providing suggestions to improve the estimation of surface flux from the $\mathrm{CO}_{2}$ mixing ratio observations.

\section{Theoretical framework}

Under situations with active vegetation and convective boundary layer conditions, plant assimilation uptake $\left(\overline{w^{\prime} c^{\prime}}<\right.$ $0)$ and the $\mathrm{CO}_{2}$ exchange between $\mathrm{CBL}$ and $\mathrm{FA}\left(\overline{w^{\prime} c^{\prime}}>0\right.$ or $\overline{w^{\prime} c^{\prime}} \approx 0$ ) drive the $\mathrm{CO}_{2}$ evolution in the diurnal boundary layer. For the sake of simplicity, the contribution of the horizontal advection of $\mathrm{CO}_{2}$ is omitted. To our opinion, this is the main concern that can be made to the formulation. Accurate measurements and modeling of advection are generally quite difficult so the uncertainties in the estimated advection can be relatively large and this could lead to non-negligible errors in the simulated $\mathrm{CO}_{2}$ mixing ratios, and in the inferred $\mathrm{CO}_{2}$ surface fluxes. Recently, tall tower measurements have been successfully used to estimate $\mathrm{CO}_{2}$ advection (Yi et al., 2000, 2008; Sun et al., 2007; Aubinet et al., 2010).

Under these conditions, mixed-layer theory assumptions are valid and they can be used to determine the role of boundary layer dynamics on $\mathrm{CO}_{2}$ evolution. In mixed-layer theory, it is assumed that the $\mathrm{CO}_{2}$ mixing ratio is constant with height inside the boundary layer. Mixed-layer theory has been already used to analyze the evolution of the boundary layer growth and some of its compounds (Culf et al., 1997; Vilà-Guerau de Arellano et al., 2004, 2009). The novelty of the present work if that, for the first time, the boundary layer uncertainties that influence $\mathrm{CO}_{2}$ mixing ratio evolution is the main goal of the study.
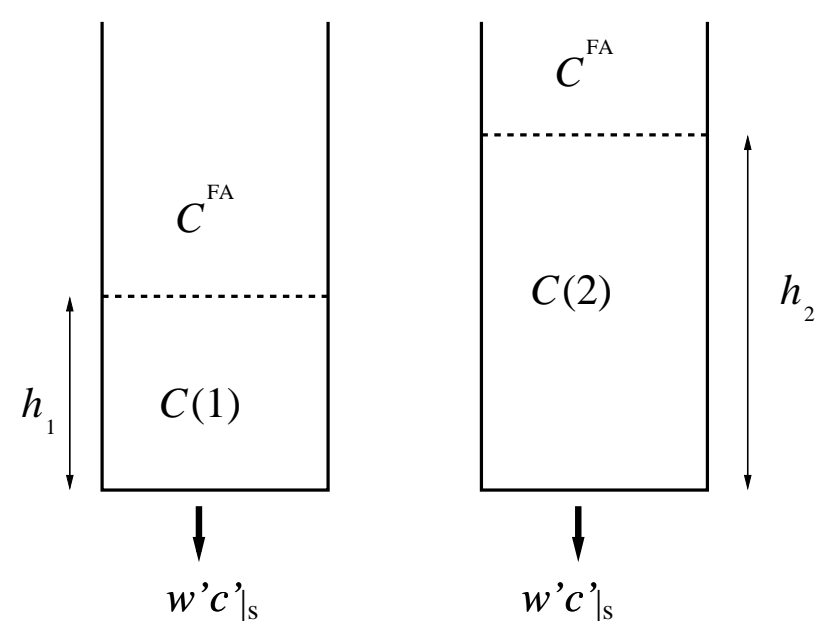

Fig. 1. Sketch of the evolution of the bulk $\mathrm{CO}_{2}$ mixing ratio quantity by using the integral from of the mixed-layer equations. The growth of the boundary layer from $h_{1}$ to $h_{2}$ depends on the heat and moisture budgets. Notice that we are assuming a negative flux for $\mathrm{CO}_{2}$ that is characteristic of the assimilation by plants during daytime and only vertical exchange processes are taken into account.

The boundary layer is separated from the free atmosphere by a thermal capping inversion caused by an increase of the potential temperature (Tennekes, 1973; Tennekes and Driedonks, 1981; Culf et al., 1997). When boundary layer grows it incorporates a new layer of free atmospheric air with different properties into the mixed-layer (see Fig. 1). It is assumed that the air masses mix instantaneously. Consequently, the new concentration only depends on the surface flux and on the growth rate of the boundary layer depth. This $\mathrm{CO}_{2}$-budget equation is analytically expressed as:

$\frac{\partial}{\partial t}(C h)=\left.\overline{w^{\prime} c^{\prime}}\right|_{s}+C^{\mathrm{FA}} \frac{\partial\left(h-h_{0}\right)}{\partial t}$,

where $h_{0}$ and $h$ are the initial and the instantaneous boundary layer depth; $C$ is the carbon dioxide mixing ratio vertically integrated between the surface and $h ; C^{\mathrm{FA}}$ is the $\mathrm{CO}_{2}$ mixing ratio in the free atmosphere, just above the inversion; and $\left.\overline{w^{\prime} c^{\prime}}\right|_{s}$ is the time-dependent surface flux of $\mathrm{CO}_{2}$. In this equation all the variables except $h_{0}$ are time dependent. The terms of this equation can be physically interpreted as the variation of the $\mathrm{CO}_{2}$ mixing ratio distributed in the mixedlayer due to the assimilation of $\mathrm{CO}_{2}$ by plants (negative sign during daytime), and to the mixing with $\mathrm{CO}_{2}$ mixing ratio in the free atmosphere $\left(C^{\mathrm{FA}}\right)$ because of the growth of the boundary layer.

In a zeroth-order approximation, the $\mathrm{CO}_{2}$ mixing ratio just above the inversion reads:

$C^{\mathrm{FA}}=C_{0}^{\mathrm{FA}}+\gamma_{c}\left(h-h_{0}\right)$,

where $C_{0}^{\mathrm{FA}}$ is the value of the $\mathrm{CO}_{2}$ mixing ratio just above the inversion when $h=h_{0}$, and $\gamma_{c}$ is the vertical gradient 
of $\mathrm{CO}_{2}$ mixing ratio in the free atmosphere, above the mixed layer, which is usually considered constant during one day. If $\gamma_{c} \neq 0$, then $C_{0}^{\mathrm{FA}}$ corresponds to the morning value of $C^{\mathrm{FA}}$. However, if $\gamma_{c}=0, C_{0}^{\mathrm{FA}}$ is the $\mathrm{CO}_{2}$ mixing ratio in the free atmosphere during the whole day. Consequently, $C^{\mathrm{FA}}$ depends on time through $h$. For this reason, it is not explicitly included in the right-hand side time derivative of Eq. (1) because its change cannot modify $C$ unless the boundary layer is growing. That is, $C^{\mathrm{FA}}$ does not depend explicitly on time.

The budget equation of $\mathrm{CO}_{2}(1)$ is taken as a starting point of the derivation of the relationships that connect $\mathrm{CO}_{2}$ temporal variation to the boundary layer variables. In the Appendix we provide a full derivation of the classical mixed layer equation from the budget Eq. (1).

\section{1 $\mathrm{CO}_{2}$ mixing ratio: forward expressions}

By substituting (2) into (1), and assuming $\gamma_{c}$ constant with time during one day, Eq. (1) becomes:

$$
\frac{\partial}{\partial t}(C h)=\left.\overline{w^{\prime} c^{\prime}}\right|_{s}+\frac{\gamma_{c}}{2} \frac{\partial}{\partial t}\left[\left(h-h_{0}\right)^{2}\right]+C_{0}^{\mathrm{FA}} \frac{\partial\left(h-h_{0}\right)}{\partial t} .
$$

This equation is then integrated on time from $t_{0}$ to $t$ obtaining:

$$
C h-C_{0} h_{0}=\left.\int_{t_{0}}^{t} \overline{w^{\prime} c^{\prime}}\right|_{s} d t+\frac{\gamma_{c}}{2}\left(h-h_{0}\right)^{2}+C_{0}^{\mathrm{FA}}\left(h-h_{0}\right) .
$$

Consequently, the time evolution of the mixing ratio of $\mathrm{CO}_{2}$ in the boundary layer reads:

$$
C=C_{0} \frac{h_{0}}{h}+C_{0}^{\mathrm{FA}}\left(1-\frac{h_{0}}{h}\right)+\frac{\gamma_{c}}{2 h}\left(h-h_{0}\right)^{2}+\frac{t-t_{0}}{h}\left\langle\left.\overline{w^{\prime} c^{\prime}}\right|_{s}\right\rangle,
$$

where $\left\langle\left.\overline{w^{\prime} c^{\prime}}\right|_{s}\right\rangle=\left[\left.\int_{t_{0}}^{t} \overline{w^{\prime} c^{\prime}}\right|_{s} d t\right] /\left(t-t_{0}\right)$ is the $\mathrm{CO}_{2}$ mean surface flux over the integration period. If the different terms of this equation are compared in typical midlatitude summer conditions it can be concluded that the third right-hand side term of Eq. (5) is two order of magnitude smaller than the first two terms. Consequently, $C$ approximately evolves with $h^{-1}$. Notice that the last term is the only one depending on the integration period (elapsed time from $t_{0}$ ), $t-t_{0}$.

From this equation we derive how the errors made in boundary layer dynamics and boundary conditions propagate in the modeled $\mathrm{CO}_{2}$ mixing ratio. By taking partial derivatives in (5), the dependance of $C$ to the key variables in the boundary layer dynamics ( $h$ and its initial morning value, $h_{0}$ ) and the $\mathrm{CO}_{2}$ characteristics $\left(C_{0}, C_{0}^{\mathrm{FA}}, \gamma_{c}\right.$, and surface flux $)$ are derived (Jacobs and De Bruin, 1992). The expressions reads:

$\frac{\partial C}{\partial C_{0}}=\frac{h_{0}}{h}$,

$$
\frac{\partial C}{\partial C_{0}^{\mathrm{FA}}}=1-\frac{h_{0}}{h},
$$

$$
\begin{aligned}
& \frac{\partial C}{\partial \gamma_{c}}=\frac{\left(h-h_{0}\right)^{2}}{2 h}, \\
& \frac{\partial C}{\partial \gamma_{c}}=\frac{\left(h-h_{0}\right)^{2}}{2 h}, \\
& \frac{\partial C}{\partial h_{0}}=-\gamma_{c}+\frac{1}{h}\left[\gamma_{c} h_{0}+C_{0}-C_{0}^{\mathrm{FA}}\right], \\
& \frac{\partial C}{\partial h}=\frac{\gamma_{c}}{2}+\frac{1}{h^{2}}\left[h_{0}\left(C_{0}^{\mathrm{FA}}-C_{0}\right)-\frac{\gamma_{c} h_{0}^{2}}{2}-\left(t-t_{0}\right)\left\langle\left.\overline{\left\langle w^{\prime} c^{\prime}\right.}\right|_{s}\right\rangle\right], \\
& \frac{\partial C}{\partial\left\langle\left.\overline{w^{\prime} c^{\prime}}\right|_{s}\right\rangle}=\frac{t-t_{0}}{h} .
\end{aligned}
$$

Assuming that the error on each considered variable influencing $\mathrm{CO}_{2}$ evolution is small, the sensitivities are linearly related to the error in the $\mathrm{CO}_{2}$ mixing ratio, $C$, through the following relation (Jacobs and De Bruin, 1992):

$\delta C=\sum_{\phi}\left|\frac{\partial C}{\partial \phi}\right| \cdot|\delta \phi|$,

where $\phi$ denotes the different variables influencing the evolution of $C$ considered here: $C_{0}, C_{0}^{\mathrm{FA}}, h, h_{0}, \gamma_{c},\left\langle\left.\overline{w^{\prime} c^{\prime}}\right|_{s}\right\rangle$. Equation (13) also assumes that $h$ does not depend on $h_{0}$, since their dependence is not taken into account in Eq. (11). In practice, an error in $h_{0}$ can propagate to $h$ depending on the situation. For example, if $h_{0}$ is obtained from a radiosounding measurement done in the morning and the subsequent evolution of $h$ is simulated, then the error in $h_{0}$ propagates to $h$. In this case the dependence $\partial h / \partial h_{0}$ should also be considered in the sensitivity to $h$. This dependence can be analytically obtained from the mixed-layer equations. However, if $h$ is measured also at later time when $C$ is evaluated, the errors in $h_{0}$ and $h$ can be completely independent. For simplicity, the latter case is assumed in the above equations and in the following analysis.

Equations (6)-(12) are grouped below according to their dependence on the boundary layer depth:

$\frac{\partial C}{\partial \gamma_{c}} \sim O(h)$,

$\frac{\partial C}{\partial C_{0}}, \frac{\partial C}{\partial C_{0}^{\mathrm{FA}}}, \frac{\partial C}{\partial h_{0}}, \frac{\partial C}{\partial\left\langle\left.\overline{w^{\prime} c^{\prime}}\right|_{s}\right\rangle} \sim O\left(h^{-1}\right)$,

$\frac{\partial C}{\partial h} \sim O\left(h^{-2}\right)$. 
Consequently, $\partial C / \partial \gamma_{c}$ increases with the boundary layer depth. $\partial C / \partial C_{0}$ and $\partial C / \partial h_{0}$ decrease with the boundary layer depth. $\partial C / \partial C_{0}^{\mathrm{FA}}$ has the same dependence with $h$ but it increases with the boundary layer depth because of the negative coefficient multiplying $h$ in Eq. (7).

The evolution of $\partial C / \partial h$ and $\partial C / \partial\left\langle\left.\overline{w^{\prime} c^{\prime}}\right|_{s}\right\rangle$ also depends on $t-t_{0}$. Regarding the sensitivity to the boundary layer depth, by analyzing Eq. (11), it can be concluded that, if $h_{0} \neq$ 0 , and $\Delta C_{0} \neq 0$, usually $h_{0}\left(C_{0}^{\mathrm{FA}}-C_{0}\right) \gg\left(t-t_{0}\right)\left\langle\left.\overline{w^{\prime} c^{\prime}}\right|_{s}\right\rangle$ for any integration period, and consequently $\partial C / \partial h$ decreases with the square of the boundary layer depth. The evolution of the sensitivity to $\mathrm{CO}_{2}$ surface flux is more complicated and it will be analyzed separately.

In Sect. 4, we make use of these equations to quantify the impact of each variable on the bulk $\mathrm{CO}_{2}$ mixing ratio.

\section{$2.2 \mathrm{CO}_{2}$ surface flux: inverse expressions}

From Eq. (4) an expression is obtained for the dependence of $\mathrm{CO}_{2}$ surface flux on atmospheric properties. This expression explicitly provides the dependence of this retrieved surface flux to boundary layer dynamics and $\mathrm{CO}_{2}$ characteristics. The averaged inferred surface flux of carbon dioxide reads:

$\left\langle\left.\overline{w^{\prime} c^{\prime}}\right|_{s}\right\rangle=\frac{1}{t-t_{0}}\left[C h-C_{0} h_{0}-C_{0}^{\mathrm{FA}}\left(h-h_{0}\right)-\frac{\gamma_{c}}{2}\left(h-h_{0}\right)^{2}\right]$.

By using this equation, the dependence of the uncertainties in the inferred $\mathrm{CO}_{2}$ surface flux to errors in the dynamics and $\mathrm{CO}_{2}$ characteristics of boundary layer is:

$\frac{\partial\left\langle\left.\overline{w^{\prime} c^{\prime}}\right|_{s}\right\rangle}{\partial C_{0}}=\frac{-h_{0}}{t-t_{0}}$,

$\frac{\partial\left\langle\left.\overline{w^{\prime} c^{\prime}}\right|_{s}\right\rangle}{\partial C_{0}^{\mathrm{FA}}}=\frac{h_{0}-h}{t-t_{0}}$,

$\frac{\partial\left\langle\left.\overline{w^{\prime} c^{\prime}}\right|_{s}\right\rangle}{\partial \gamma_{c}}=-\frac{\left(h-h_{0}\right)^{2}}{2\left(t-t_{0}\right)}$,

$\frac{\partial\left\langle\left.\overline{w^{\prime} c^{\prime}}\right|_{s}\right\rangle}{\partial h_{0}}=\frac{1}{t-t_{0}}\left[C_{0}^{\mathrm{FA}}-C_{0}+\gamma_{c}\left(h-h_{0}\right)\right]$,

$\frac{\partial\left\langle\left.\overline{w^{\prime} c^{\prime}}\right|_{s}\right\rangle}{\partial h}=\frac{1}{t-t_{0}}\left[C-C_{0}^{\mathrm{FA}}-\gamma_{c}\left(h-h_{0}\right)\right]$

$\frac{\partial\left\langle\left.\overline{w^{\prime} c^{\prime}}\right|_{s}\right\rangle}{\partial C}=\frac{h}{t-t_{0}}$
Taking into account that all the equations depend on $t-t_{0}$, these equations are again grouped according to boundary layer depth dependence:

$$
\begin{aligned}
& \frac{\partial\left\langle\left.\overline{w^{\prime} c^{\prime}}\right|_{s}\right\rangle}{\partial \gamma_{c}} \sim O\left(h^{2}\right), \\
& \frac{\partial\left\langle\left.\overline{w^{\prime} c^{\prime}}\right|_{s}\right\rangle}{\partial C_{0}^{\mathrm{FA}}}, \frac{\partial\left\langle\left.\overline{w^{\prime} c^{\prime}}\right|_{s}\right\rangle}{\partial h_{0}}, \frac{\partial\left\langle\left.\overline{w^{\prime} c^{\prime}}\right|_{s}\right\rangle}{\partial h}, \frac{\partial\left\langle\left.\overline{w^{\prime} c^{\prime}}\right|_{s}\right\rangle}{\partial C} \sim O(h), \\
& \frac{\partial\left\langle\left.\overline{w^{\prime} c^{\prime}}\right|_{s}\right\rangle}{\partial C_{0}} \sim O\left(h^{0}\right) .
\end{aligned}
$$

These equations show that the time evolution of all the sensitivities except $\partial\left\langle\left.\overline{w^{\prime} c^{\prime}}\right|_{s}\right\rangle / \partial C_{0}$ depends on the relation between the integration period and the boundary layer depth and none of them necessarily increase or decrease with the boundary layer depth. The sensitivity to uncertainties in the morning value of the $\mathrm{CO}_{2}$ bulk mixing ratio, $\partial\left\langle\left.\overline{w^{\prime} c^{\prime}}\right|_{s}\right\rangle / \partial C_{0}$, is the same for all the studied boundary layers because only depends on the initial boundary layer depth and on the integration period (see Eq. 18). Consequently, its absolute value decreases with time.

Notice that besides the assumptions and approximations considered before, here it is additionally assumed that $C$ is directly measured at different times and so the errors in $C$ do not depend on the other variables.

\section{Study case}

We first evaluate the ability of a mixed-layer model to reproduce the observed diurnal variability of the CBL. Subsequently, we discuss the sensitivity of the temporal evolution of the $\mathrm{CO}_{2}$ mixing ratio and the inferred surface flux to uncertainties associated to boundary layer dynamics and $\mathrm{CO}_{2}$ distribution.

\subsection{Diurnal evolution of $\mathrm{CO}_{2}$}

At the Cabauw site, located in the center of The Netherlands, observations of thermodynamic and $\mathrm{CO}_{2}$ variables are taken continuously at different heights. The site lies in an open field nearly completely covered by short grass which extends for several hundreds of squared meters (see Beljaars and Bosveld (1997) for a detailed description of the site). At this site, vertical profiles of wind, temperature, humidity and $\mathrm{CO}_{2}$ are measured along a 213-meters meteorological tower. Measurements for temperature are taken at 2, 10, 20, 40, 80, 140 , and $200 \mathrm{~m}$, whereas $\mathrm{CO}_{2}$ mixing ratios are recorded at $20,60,120$, and $200 \mathrm{~m}$. $\mathrm{CO}_{2}$ observations have previously been described by Werner et al. (2006) and Vermeulen et al. (2011). 


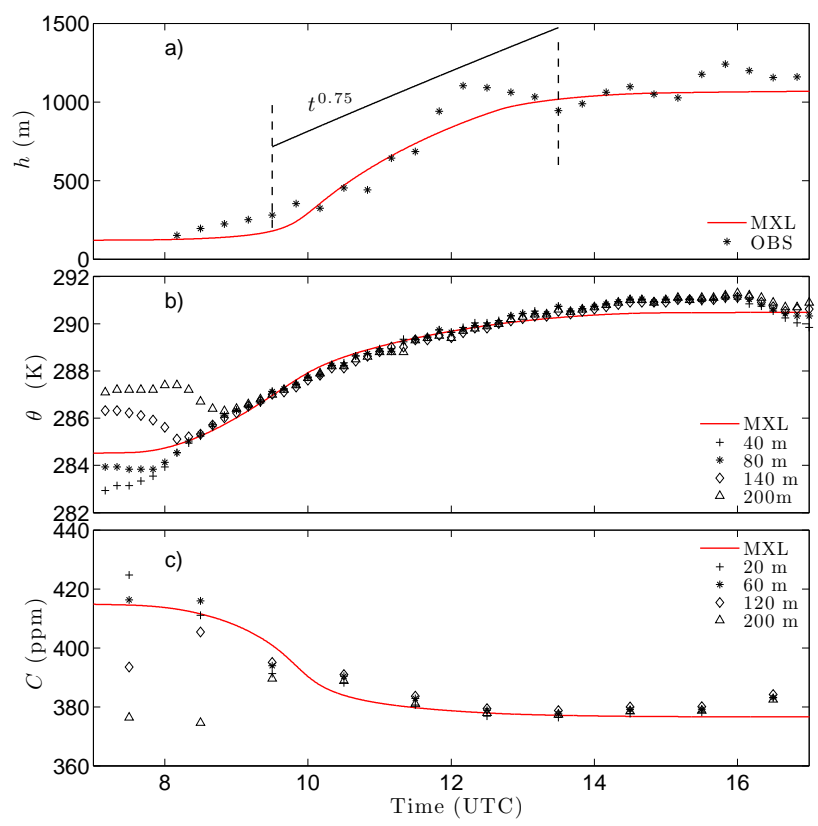

Fig. 2. Observed (symbols) and simulated by means of mixed layer model (red solid lines) diurnal evolution during 25 September 2003 of (a) the boundary layer depth, (b) potential temperature and (c) $\mathrm{CO}_{2}$ mixing ratio. The initial and prescribed values of the mixed layer simulation are presented in Table 1. As a reference, the evolution of the boundary layer depth following with $t^{0.75}$ is indicated by a black solid line. The vertical dashed lines are the boundaries between the different regimes explained in the text.

Fluxes of momentum, sensible and latent heat and $\mathrm{CO}_{2}$ are also measured at $10 \mathrm{~Hz}$ at $5,60,100$, and $180 \mathrm{~m}$ height. For further description on flux measurements, see Bosveld et al. (2004) and Werner et al. (2006).

A convective day with well-mixed boundary layer has been selected to study simultaneously the temporal evolution of the $\mathrm{CO}_{2}$ mixing ratio, and potential temperature. 25 September 2003 was a convective day with negligible large scale advection and few clouds observed (Casso et al., 2008). The nearly sinusoidal pattern in time of the measured short wave downward radiation (not shown) confirms the presence of nearly clear skies. Measurements from the radiosonde performed at De Bilt (located around $40 \mathrm{~km}$ from the site) at 12:00 UTC indicate a well mixed layer of about $1200 \mathrm{~m}$ deep for that day, which is in agreement with wind profiler measurements. Constant $4-5 \mathrm{~m} \mathrm{~s}^{-1}$ winds regardless of height were measured during the day.

During that day the budget of the $\mathrm{CO}_{2}$ mixing ratio (Stull, 1988 ) is mainly controlled by the divergence of the flux term. Advection accounts for less than $20 \%$ of the storage term (Casso et al., 2008; Pino and Vilà-Guerau de Arellano, 2010). It is therefore an appropriate case to apply our theoretical relationships.

\subsection{Mixed layer numerical experiment}

To analyze and reproduce the observed evolution of the CBL and the $\mathrm{CO}_{2}$ distribution, a mixed-layer model (Tennekes and Driedonks, 1981; Vilà-Guerau de Arellano et al., 2004; Pino et al., 2006) has been used. The model calculates simultaneously the evolution of the boundary layer depth $(h)$ necessary to study the $\mathrm{CO}_{2}$ budget and the uncertainties in $\mathrm{CO}_{2}$ mixing ratio and the inferred surface flux associated to the boundary layer processes and $\mathrm{CO}_{2}$ characteristics presented in Eqs. (6)-(12) and (18)-(23). The MXL model simulation run for 12 hours starting at 06:00 UTC.

Table 1 shows the initial values, based on the observations for the selected day, of the potential temperature, specific humidity and $\mathrm{CO}_{2}$ mixing ratio in the mixed layer $\left(\theta_{0}, q_{0}\right.$, and $C_{0}$ respectively), their respective inversion jumps and gradients in the FA and the temporal evolution of the surface fluxes prescribed in the mixed layer model simulation. The prescribed surface flux follows a sinusoidal function to account for the evolution over time based on the observations. The change of sign at the morning in the sensible heat flux (SH) and latent heat flux (LE) happens at 07:30 UTC and 06:00 UTC respectively and they were not considered in the mixed-layer simulation where initial zero surface heat fluxes were used.

As Fig. 2 shows, MXL results compare satisfactorily to the observed diurnal evolution of the boundary layer depth, potential temperature, and $\mathrm{CO}_{2}$ mixing ratio in the mixedlayer. We summarize the main findings of the evaluation:

1. Mixed-layer model results reproduce the boundary layer depth observations, except at the middle of the day when scattered clouds were observed above the site, which could have affected the measurements of the boundary layer depth by the wind profiler. This fact can be observed in Fig. 2a by the increase of the observed $h$ around 12:00 UTC. Three different regimes of the growth of the boundary layer are observed. Approximately from 06:00 to 09:00 UTC the boundary layer is approximately constant; between 09:00 and 13:00 UTC the boundary layer grows fast with $t^{n}$, and $n>0.5$. From this moment, when the surface heat fluxes decrease, the boundary layer growth is again very small.

2. The observed diurnal evolution of potential temperature and $\mathrm{CO}_{2}$ mixing ratio at different tower levels and simulated with the MXL model for the 25 September 2003 is shown in Fig. 2b, c. A total increase of about $6 \mathrm{~K}$ is observed for the potential temperature from 07:00 to 16:00 UTC and measurements of the $\mathrm{CO}_{2}$ mixing ratio at $20 \mathrm{~m}$ show a decrease of $40 \mathrm{ppm}$ during the same period. The morning transition from a stable boundary layer to an unstable mixed layer occurs between 08:00 and 09:00 UTC. The decrease of $30 \mathrm{ppm}$ of the $\mathrm{CO}_{2}$ mixing ratio at $20 \mathrm{~m}$ between 07:00 and 09:00 UTC indicates the mixing of entrained air with low $\mathrm{CO}_{2}$ content 
Table 1. Initial and prescribed values used for the mixed layer model based on the observations taken at Cabauw (The Netherlands) on 25 September 2003. The value of $\gamma_{\theta}$ is prescribed in the mixed-layer model following van Heerwaarden et al. (2010). The conversion factor to transform mixing ratio to mass concentration for $\mathrm{CO}_{2}$ at $T=288 \mathrm{~K}$ is $1 \mathrm{ppm}=1.862 \mathrm{mg} \mathrm{m}^{-3}$.

\begin{tabular}{|c|c|}
\hline Property & Value \\
\hline \multicolumn{2}{|l|}{ Boundary layer properties } \\
\hline Initial boundary layer depth, $h_{0}(\mathrm{~m})$ & 120 \\
\hline Large scale subsidence velocity, $w_{s}\left(\mathrm{~m} \mathrm{~s}^{-1}\right)$ & 0 \\
\hline \multicolumn{2}{|l|}{ Heat } \\
\hline$\left.\overline{w^{\prime} \theta^{\prime}}\right|_{s},(07: 30-15: 00 \mathrm{UTC})\left(\mathrm{K} \mathrm{m} \mathrm{s}^{-1}\right)$ & $0.08 \sin \left(\frac{\pi(t-5400)}{27000}\right)$ \\
\hline Entrainment to surface sensible flux ratio & 0.3 \\
\hline$\theta_{0}(\mathrm{~K})$ & 284.5 \\
\hline$\Delta \theta_{0}(\mathrm{~K})$ & 3.5 \\
\hline \multicolumn{2}{|l|}{$\gamma_{\theta}\left(\mathrm{Km}^{-1}\right)$} \\
\hline$h<950 \mathrm{~m}$ & $3.6 \times 10^{-3}$ \\
\hline$h>950 \mathrm{~m}$ & $15 \times 10^{-3}$ \\
\hline \multicolumn{2}{|l|}{ Moisture } \\
\hline$\left.\overline{\overline{w^{\prime} q^{\prime}}}\right|_{s},(06: 00-18: 00$ UTC $)\left(\mathrm{g} \mathrm{kg}^{-1} \mathrm{~m} \mathrm{~s}^{-1}\right)$ & $0.087 \sin \left(\frac{\pi t}{43200}\right)$ \\
\hline$q_{0}\left(\mathrm{~g} \mathrm{~kg}^{-1}\right)$ & 4.3 \\
\hline$\Delta q_{0}\left(\mathrm{~g} \mathrm{~kg}^{-1}\right)$ & -0.8 \\
\hline$\gamma_{q}\left(\mathrm{~g} \mathrm{~kg}^{-1} \mathrm{~m}^{-1}\right)$ & $-1.5 \times 10^{-3}$ \\
\hline \multicolumn{2}{|l|}{ Carbon dioxide } \\
\hline$\left.\overline{\overline{w^{\prime} c^{\prime}}}\right|_{s},(08: 00-15: 30 \mathrm{UTC})\left(\mathrm{ppm} \mathrm{m} \mathrm{s}^{-1}\right)$ & $-0.1 \sin \left(\frac{\pi(t-7200)}{27000}\right)$ \\
\hline$C_{0}(\mathrm{ppm})$ & 415 \\
\hline$\Delta C_{0}(\mathrm{ppm})$ & -40 \\
\hline$\gamma_{c}\left(\mathrm{ppm} \mathrm{m}^{-1}\right)$ & $-3 \times 10^{-3}$ \\
\hline
\end{tabular}

and the uptake by plants. The vertical gradients of potential temperature and the $\mathrm{CO}_{2}$ mixing ratio tend rapidly to zero in the upper levels during this morning transition until both scalars reach a constant value with height once the depth of the growing mixed layer reaches the level of 250 $\mathrm{m}$ at 09:00 UTC. The strong diurnal variability of both scalars has a clear maximum for the potential temperature of $291 \mathrm{~K}$ at around 16:00 UTC. Similarly, a minimum of $375 \mathrm{ppm}$ for the $\mathrm{CO}_{2}$ mixing ratio occurs earlier at 14:00 UTC. This strong variability of the $\mathrm{CO}_{2}$ mixing ratio during the transition from a stable boundary layer to an unstable mixed layer was also observed by Yi et al. (2000) and Werner et al. (2006). The observed features of the evolution of $\theta$ and the $\mathrm{CO}_{2}$ mixing ratio were well reproduced with the MXL model.

\section{$4 \mathrm{CO}_{2}$ sensitivity to boundary-layer dynamics}

The analytical equations presented in Sect. 2 enable us to determine the sensitivity of the atmosphere- $\mathrm{CO}_{2}$ system to boundary layer dynamics and surface processes. A full set of mixed-layer numerical experiments has been performed by changing the initial inversion strength, $\Delta \theta_{0}$, and the free atmospheric lapse rate, $\gamma_{\theta}$, considered constant during the day. $40 \times 40$ numerical experiments were carried out ranging from $\gamma_{\theta} \in\left[10^{-3}, 10^{-2}\right]\left(\mathrm{K} \mathrm{m}^{-1}\right)$ and $\Delta \theta_{0} \in[0.2,5](\mathrm{K})$. For all these cases, to simplify the analysis, the $\mathrm{CO}_{2}$ surface flux is constant during the day, $\left\langle\left.\overline{w^{\prime} c^{\prime}}\right|_{s}\right\rangle=-0.1 \mathrm{ppm} \mathrm{m} \mathrm{s}^{-1}$.

To introduce the sensitivity analysis, it is convenient to show first how the boundary layer depth obtained with the mixed-layer model evolves with time for different cases and what is the subsequent influence on the bulk $\mathrm{CO}_{2}$ mixing ratio (see Fig. 3). First, the same case as presented before but 


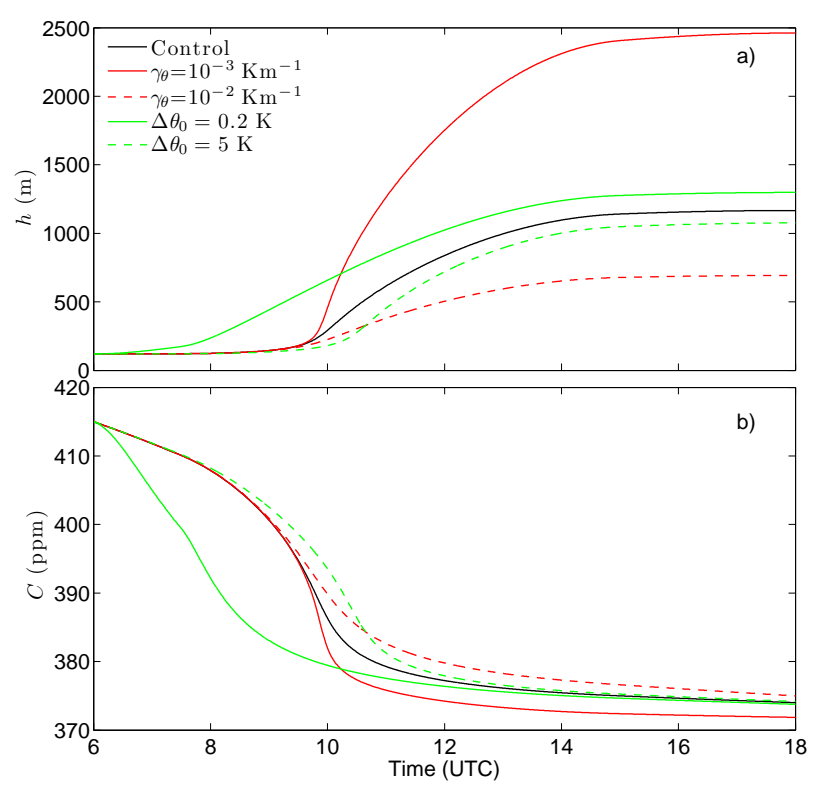

Fig. 3. Time evolution of (a) the boundary layer depth and (b) the $\mathrm{CO}_{2}$ mixing ratio obtained with the mixed layer model for different values of $\gamma_{\theta}$ and $\Delta \theta_{0}$. The control case has $\gamma_{\theta}=$ $3.6 \times 10^{-3} \mathrm{~K} \mathrm{~m}^{-1}$, and $\Delta \theta_{0}=3.5 \mathrm{~K}$. The other variables have the values presented in Table 1 . In the figure legend, if the potential temperature lapse rate or inversion strength is not shown, the value for the control case applies.

with $\gamma_{\theta}=0.0036 \mathrm{~K} \mathrm{~m}^{-1}$ constant in time is considered as the control case for the sensitivity analysis (black solid line). Additionally, four more cases are shown in the figure. In these cases, the value of $\gamma_{\theta}$ or $\Delta \theta_{0}$ is changed from the control value to one of the extremes values considered in the sensitivity analysis $\left(\gamma_{\theta}=10^{-3}\right.$ or $10^{-2} \mathrm{~K} \mathrm{~m}^{-1}$, and $\Delta \theta_{0}=0.2$, or $5 \mathrm{~K}$ ). As shown, the three different regimes of the boundary layer growth identified in Fig. 2 can be also observed here if the initial inversion strength is not too small. The evolution of the boundary layer depth has a clear signature on $C$ not only in the final values but also in the evolution during the day. In short, except for the case with $\Delta \theta_{0}=0.2 \mathrm{~K}$ (green solid line of Fig. 3), due to the large initial inversion strength prescribed, and the small surface heat fluxes during the morning, the growth of the boundary layer is almost suppressed and the evolution of $C$ is mainly controlled by the $\mathrm{CO}_{2}$ surface fluxes approximately from 06:00 to 10:00 UTC. From this moment, when $\Delta \theta$ is weaker for all the cases, $h$ grows fast except for the case with $\gamma_{\theta}=10^{-2} \mathrm{~K} \mathrm{~m}^{-1}$ (red dashed line of Fig. 3a) and consequently $C$ decreases due to the vegetation uptake but also to the air entering from the FA which has a lower $\mathrm{CO}_{2}$ mixing ratio. Consequently, the differences obtained between the boundary layers in the $\mathrm{CO}_{2}$ mixing ratio at the end of the day are only caused by the different entrainment regimes. To give the reader an impression on the impact of $h$, an error of $\delta h \approx 1300 \mathrm{~m}$ in the calcula- tion or measurement of the boundary layer depth at the end of the day (the difference between the control case and the case with $\gamma_{\theta}=10^{-3} \mathrm{~K} \mathrm{~m}^{-1}$ (black and red solid lines of Fig. 3) produces a change in $C$ of $\delta C \approx 2 \mathrm{ppm}$.

\subsection{Evolution of $\mathrm{CO}_{2}$ mixing ratio uncertainties}

We begin by analyzing the normalized sensitivities to infer the most important variables influencing the $\mathrm{CO}_{2}$ mixing ratio. The Eqs. (6)-(12) are normalized following Jacobs and De Bruin (1992). We denote the normalized (relative) sensitivity of $\mathrm{CO}_{2}$ mixing ratio to the variable $\phi$ as:

$\mathrm{RSC}_{\phi}=\frac{\partial C}{\partial \phi} \cdot \frac{\phi}{C}$,

where $\partial C / \partial \phi$ is obtained from Eqs. (6)-(12). $\mathrm{RSC}_{\phi}=0$ means that the $\mathrm{CO}_{2}$ mixing ratio in the boundary layer is independent of variable $\phi$.

By using expression (27), Fig. 4 shows the time evolution of the relative sensitivities obtained by normalizing the Eqs. (6)-(12) for the control case. At midday, $\mathrm{CO}_{2}$ mixing ratio is mainly sensitive to errors on the initial $\mathrm{CO}_{2}$ mixing ratio in the boundary layer and in the free atmosphere, $C_{0}$, and $C_{0}^{\mathrm{FA}}$. Moreover, during the morning, it is also sensitive to errors on the boundary layer depth, $h$, and its initial value, $h_{0}$, but these sensitivities decrease during the day because of the growth of the boundary layer (from Eqs. 10, 11 it can be demonstrated that both relative sensitivities are proportional to $(C h)^{-1}$, and $C h$ increases during the day for the control case, not shown). The carbon dioxide conditions in the FA represented by $\gamma_{c}$ have almost no influence on the $\mathrm{CO}_{2}$ mixing ratio in comparison with the sensitivity to $C_{0}^{\mathrm{FA}}$. Finally, uncertainties in the $\mathrm{CO}_{2}$ surface flux have only small influence on the $\mathrm{CO}_{2}$ mixing ratio during the early morning, until 10:00 UTC, when the boundary layer of the control case hardly grows (see Fig. 3a). From this figure, we conclude that a correct prescription of the initial values of the $\mathrm{CO}_{2}$ mixing ratio in the mixed layer and in the FA and the boundary layer depth are fundamental to correctly simulate the $\mathrm{CO}_{2}$ mixing ratio at midday.

Once the main variables influencing the uncertainty of $\mathrm{CO}_{2}$ mixing ratio have been identified, the evolution of these sensitivities with time will be discussed. By considering that $C$-evolution depends on $h$, the sensitivities will be presented without normalizing them to preserve the dependence with the boundary layer depth shown in the expressions (14)-(16).

$\partial C / \partial C_{0}$, and $\partial C / \partial h_{0}$ are $O\left(h^{-1}\right)$ (see Eqs. 6, and 10). $\partial C / \partial\left\langle\left.\overline{w^{\prime} c^{\prime}}\right|_{s}\right\rangle$ have the same dependency, but also depends on the integration period (see Eq. (12)), and it will be studied separately. Taking into account that $C$ approximately evolves with $h^{-1}$ (see Eq. 5), $\partial C / \partial C_{0}$, and $\partial C / \partial h_{0}$ can be qualitatively described by using Fig. 3a and $b$. At the beginning of the day, the value of the initial inversion strength controls the growth of the boundary layer depth (see Fig. 3a), and consequently the evolution of the $C$-sensitivity to $C_{0}$, and $h_{0}$. The 
sensitivity decreases faster for the case with smallest inversion strength (green solid line of Fig. 3b). From midday, the boundary layer growth is controlled by $\gamma_{\theta}$, and, as a consequence, the time evolution of the sensitivity of the $\mathrm{CO}_{2}$ mixing ratio is also controlled by the potential temperature lapse rate, decreasing with the increasing boundary layer depth at the same rate for similar $\gamma_{\theta}$. From this analysis, we show that a correct knowledge of the values of $C_{0}$, or $h_{0}$ becomes less important when $h \gg h_{0}$.

The other variable having large influence on the uncertainties in $\mathrm{CO}_{2}$ mixing ratio is the initial value of the $\mathrm{CO}_{2}$ mixing ratio in the free atmosphere, $C_{0}^{\mathrm{FA}}$ (see Fig. 4). Although $\partial C / \partial C_{0}^{\mathrm{FA}} \sim O\left(h^{-1}\right)$, this sensitivity increases with the boundary layer depth due to the negative sign of the dependence (compare Eqs. 6 and 7). At the beginning of the simulation, the sensitivity is zero because the $\mathrm{CO}_{2}$ mixing ratio is mainly sensitive to the initial bulk value $C_{0}$. When the boundary layer grows, air enters in the boundary layer from the free atmosphere, and $C$ becomes more dependent to the conditions in the free atmosphere and consequently the sensitivity to this variable increases. For all the cases, as can be also concluded from Eq. (7), $\partial C / \partial C_{0}^{\mathrm{FA}}$ tends to an asymptotic value close to 1 . That is, if the boundary layer grows enough, uncertainties in the bulk morning conditions are less important, and the free atmospheric conditions control the errors made in $C$ calculation.

The evolution of $\partial C / \partial h$ is $O\left(h^{-2}\right)$ but also depends on the integration period (see Eq. 11). However, the evolution of this sensitivity is dominated, for the studied cases, by the first and second terms of Eq. (11). Then, the term containing the integration period can be neglected. Taking into account that $\gamma_{c}<0$ and the term in brackets of Eq. (11) is also negative for the studied cases, the absolute value of this sensitivity decreases with the boundary layer depth. Then, errors made in the determination of $h$ are less important to determine the uncertainties in $C$ when the day progress. For the case with lowest inversion strength, the decrease is very fast due to the large growth rate of the boundary layer depth (see Fig. 3a and Eq. 11). From noon, due to the large value of $h$ for all the simulated cases $\partial C / \partial h \approx \gamma_{c} / 2=-0.0015 \mathrm{ppm} \mathrm{m}^{-1}$ (see Eq. 11). That is, when the boundary layer is large enough, the sensitivity of $C$ to the boundary layer depth only depends on the $\mathrm{CO}_{2}$ free atmospheric characteristics represented by $\gamma_{c}$.

Although $\mathrm{CO}_{2}$ surface flux has a small relative influence on the uncertainties in $\mathrm{CO}_{2}$ mixing ratio (see Fig. 4), it is interesting to study its evolution during the day because its dependence with $h$ and the integration period, $t-t_{0}$. As Eq. (12) shows, $\partial C / \partial\left\langle\left.\overline{w^{\prime} c^{\prime}}\right|_{s}\right\rangle$ is proportional to the integration period and inversely proportional to the boundary layer depth. Figure 5 shows the time evolution of the sensitivity of $C$ to $\left\langle\left.\overline{w^{\prime} c^{\prime}}\right|_{s}\right\rangle$ for the five boundary layers presented in Fig. 3. Taking into account that $t-t_{0}$ is always increasing, its evolution depends on whether $h$ grows faster than the integration period or not. As it was already mentioned

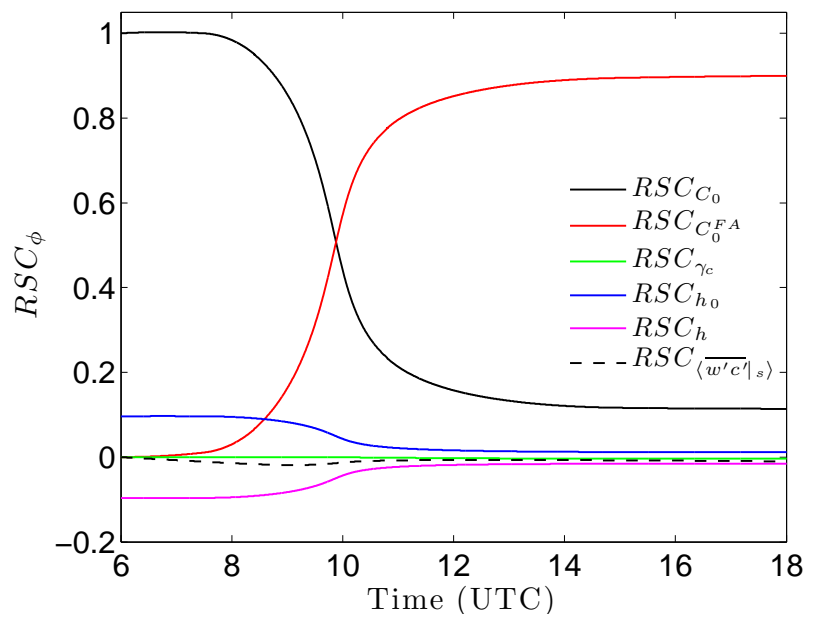

Fig. 4. Time evolution of the relative (normalized) sensitivity of the $\mathrm{CO}_{2}$ mixing ratio to all the variables $\left(\mathrm{RSC}_{\phi}\right.$, see expression 27 ) for the control case.

in the explanation of Fig. 3, the boundary layer growth can present three different regimes. During the morning, except if a small inversion strength exists, the boundary layer growth rate is small (see Fig. 3a). Consequently, the sensitivity increases until the boundary layer starts to grow faster. This fact occurs for the different studied boundary layer at different times of the day (between 08:00 and 10:00 UTC, see Fig. 3a). At this moment the sensitivity presents a maximum. Afterwards, during few hours the boundary layer is growing faster than $t-t_{0}$ and the sensitivity decreases approximately until midday when the boundary layer growth is reduced and the sensitivity increases again, but with lower rate, until the end of the simulated period. From this moment, the evolution of the sensitivity is approximately the same for all the cases and, as a consequence, it is always larger for the cases having large $\Delta \theta_{0}$ and $\gamma_{\theta}$ (smaller boundary layer depth at midday, see Fig. 3a). Summarizing, to reduce the uncertainty integration times from the morning until the time of the maximum $h$ have to be considered. Longer integration times only slightly decrease the error. From this analysis, we find that the errors in the estimation of the $\mathrm{CO}_{2}$ mixing ratio have a clear dependence with time. Moreover, it can be concluded that to estimate the $\mathrm{CO}_{2}$ mixing ratio in the mixed layer, it is basic to minimize the errors on the $\mathrm{CO}_{2}$ mixing ratio concentration in the free atmosphere (see Fig. 4).

Figure 6 shows the sensitivity of the $\mathrm{CO}_{2}$ mixing ratio to uncertainties in the morning value of the $\mathrm{CO}_{2}$ bulk mixing ratio $\left(\partial C / \partial C_{0}\right.$, contours), combined with the boundary layer depth ( $h$, red solid lines) averaged between 12:00 and 14:00 UTC for all the studied cases. These values are calculated as a function of the potential temperature lapse rate and the initial inversion strength. Large values of $\gamma_{\theta}$ and $\Delta \theta_{0}$ inhibits the boundary layer growth, and, as a consequence, increases the sensitivity to uncertainties in the morning value 


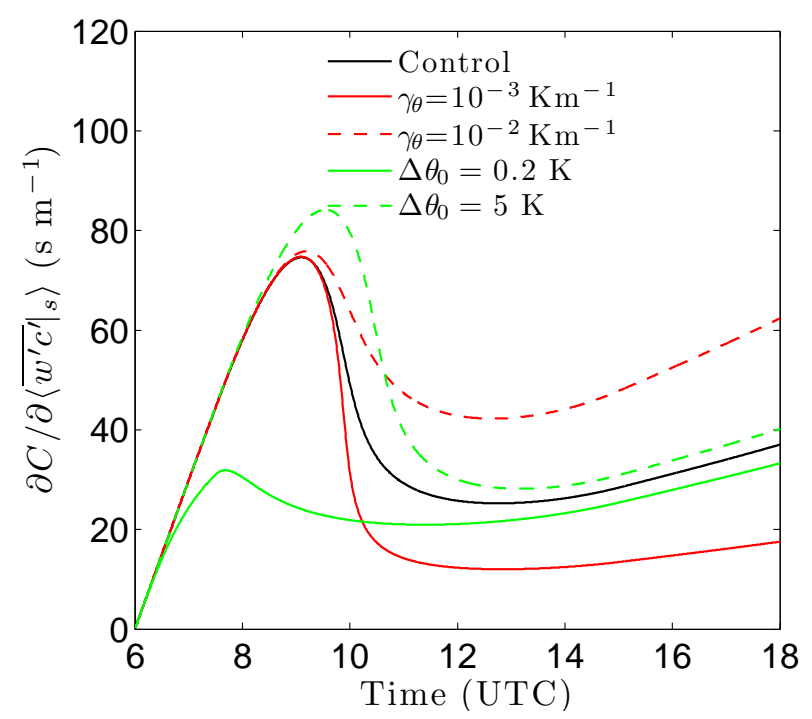

Fig. 5. Time evolution of the sensitivity of the $\mathrm{CO}_{2}$ mixing ratio to the $\mathrm{CO}_{2}$ surface flux for the same boundary layers presented in Fig. 3.

of the $\mathrm{CO}_{2}$ bulk mixing ratio. That is, this sensitivity is inversely proportional to the boundary layer depth (see Eq. 6 and compare the contours in Fig. 6). Since the bulk $\mathrm{CO}_{2}$ mixing ratio has similar sensitivity to $h_{0}$ (compare Eqs. 6, and 10) the response of $\partial C / \partial h_{0}$ presents also an inverse proportional dependence with the boundary layer depth. Notice that in the case of $\partial C / \partial h$ the dependence is proportional to $h^{-2}$ (see Eq. 11).

Despite $\partial C / \partial\left\langle\left.\overline{w^{\prime} c^{\prime}}\right|_{s}\right\rangle$ also depends on the elapsed time, Fig. 6 can be also used to qualitatively explain how the average value of $\partial C / \partial\left\langle\left.\overline{w^{\prime} c^{\prime}}\right|_{s}\right\rangle$ between 12:00 and 14:00 UTC varies for the different studied boundary layers. As Fig. 5 shows, from midday the larger the initial inversion jump, or lapse rate (smaller the boundary layer depth) is, the larger is this sensitivity.

On the contrary, the $\mathrm{CO}_{2}$ mixing ratio sensitivity to free atmospheric characteristics $\left(\partial C / \partial C_{0}^{\mathrm{FA}}\right.$ and $\left.\partial C / \partial \gamma_{c}\right)$ increase with $h$. This fact can be understood by considering that when the boundary layer grows rapidly (for small values of the potential temperature lapse rate or the initial inversion strength), more air from the free atmosphere is entrained in the mixed layer, and the $\mathrm{CO}_{2}$ characteristics of this air exert a larger influence on the bulk $\mathrm{CO}_{2}$ mixing ratio.

\subsection{Inferred $\mathrm{CO}_{2}$ surface flux}

Similar to expression (27), the relative importance of each variable, $\phi$ in the $\mathrm{CO}_{2}$ inferred surface flux is quantified by normalizing the Eqs. (18)-(23) as:

$\operatorname{RSF}_{\phi}=\frac{\partial\left\langle\left.\overline{w^{\prime} c^{\prime}}\right|_{s}\right\rangle}{\partial \phi} \cdot \frac{\phi}{\left\langle\left.\overline{w^{\prime} c^{\prime}}\right|_{s}\right\rangle}$

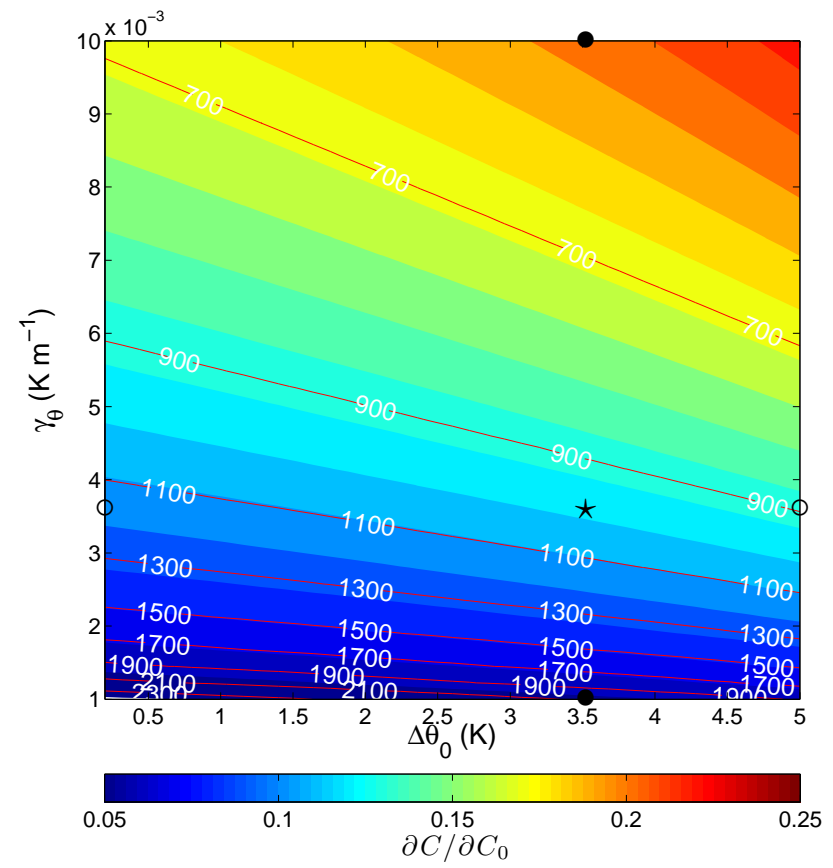

Fig. 6. $\partial C / \partial C_{0}$ (contours) and $h$ (m, red solid lines) averaged between 12:00 and 14:00 UTC as a function of $\gamma_{\theta}$ and $\Delta \theta_{0}$. The control case is shown with $\star$. The rest of the symbols show the most extreme cases: o's $\Delta \theta_{0}=0.2$, and $5 \mathrm{~K}$ with $\gamma_{\theta}=3.6 \times 10^{-3}$ and •'s $\gamma_{\theta}=10^{-3}$, and $10^{-2} \mathrm{~K} \mathrm{~m}^{-1}$ with $\Delta \theta_{0}=3.5 \mathrm{~K}$.

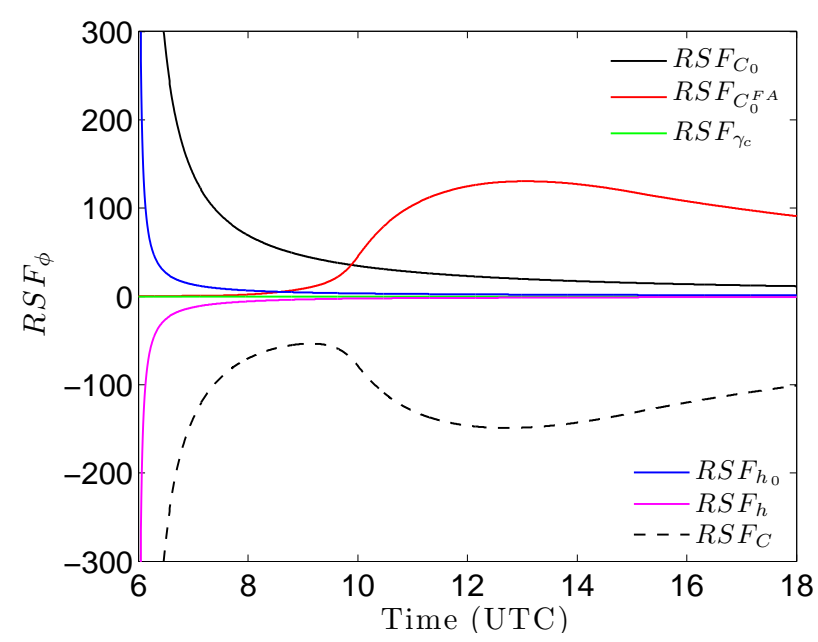

Fig. 7. Time evolution of the normalized sensitivities of the inferred $\mathrm{CO}_{2}$ surface flux to all the variables $\left(\mathrm{RSF}_{\phi}\right.$, see expression 28) for the control case.

Figure 7 shows the time evolution of the relative (normalized) sensitivities of the inferred $\mathrm{CO}_{2}$ surface flux (see expression 28) for the control case. All the studied sensitivities are inversely proportional to the elapsed time from the morning, $t-t_{0}$. For this reason, during the morning, when small elapsed times are considered, the sensitivities are very large 
except in the case of $\partial\left\langle\left.\overline{w^{\prime} c^{\prime}}\right|_{s}\right\rangle / \partial C_{0}^{\mathrm{FA}}$, and $\partial\left\langle\left.\overline{w^{\prime} c^{\prime}}\right|_{s}\right\rangle / \partial \gamma_{c}$ because during the early morning the boundary layer has hardly grown, $h \approx h_{0}$, and the free atmospheric conditions of $\mathrm{CO}_{2}$ do not play a role on the inferred surface flux (see Eqs. 19 and 20).

At midday the inferred $\mathrm{CO}_{2}$ surface flux is more sensitive to errors on the initial $\mathrm{CO}_{2}$ conditions represented by $C_{0}$ and $C_{0}^{\mathrm{FA}}$ and to the evolution of the $\mathrm{CO}_{2}$ mixing ratio itself, $C$, than to the other variables $\left(h, h_{0}\right.$, or $\left.\gamma_{c}\right)$. The sensitivity to uncertainties in the initial $\mathrm{CO}_{2}$ mixing ratio in the free atmosphere and $\mathrm{CO}_{2}$ bulk mixing ratio $\left(C_{0}^{\mathrm{FA}}\right.$ and $C$ ) have a similar evolution except during the early morning. In both cases, from 09:00 UTC the sensitivity increases with time until midday when the boundary layer growth starts to decrease. From this moment, the sensitivity decreases because the growth rate of the boundary layer is small and $t-t_{0}$ keeps on growing (see Eqs. 19 and 23). Consequently, if bulk $\mathrm{CO}_{2}$ mixing ratio is accurately measured but no information about the $\mathrm{CO}_{2}$ mixing ratio in the free atmosphere is available, the errors made in the estimation of the $\mathrm{CO}_{2}$ surface flux during the afternoon can be very large (Culf et al., 1997).

Regarding the sensitivity to the morning value of the $\mathrm{CO}_{2}$ mixing ratio, it evolves with $\left(t-t_{0}\right)^{-1}$ and it is only important during the morning.

For all the the studied variables, the sensitivity of the inferred surface flux to uncertainties in the boundary layer parameters is generally larger compared with the sensitivity of $C$ (compare the scale of the $y$-axis of Figs. 4 and 7). That is, the inferred flux obtained by inversion modeling techniques is very sensitive to the boundary layer dynamic variables. This fact can be explained if the expressions (14)-(16) are compared with expressions (24)-(25). The mixing ratio sensitivities are $O\left(h^{n}\right)$, with $n<0$ except for $\partial C / \partial \gamma_{c}$, whereas the inferred $\mathrm{CO}_{2}$ surface flux sensitivities are $O\left(h^{m}\right)$ with $m>0$. Moreover, take into account that $C$ can be several orders of magnitude larger than $\left\langle\left.\overline{w^{\prime} c^{\prime}}\right|_{s}\right\rangle$, and consequently the same difference applies to the normalization factors.

We will focus on the most relevant variables influencing the errors made on the retrieval $\mathrm{CO}_{2}$ surface flux: $C_{0}, C_{0}^{\mathrm{FA}}$ and $C$. The sensitivity of the retrieved $\mathrm{CO}_{2}$ surface flux to uncertainties in $C_{0}$ only depends on $t-t_{0}$ (see Eq. 18). Then, all the studied cases present the same evolution of this sensitivity. This sensitivity decreases with time; as the day progresses the influence of the initial value of the bulk $\mathrm{CO}_{2}$ mixing ratio is smaller.

The sensitivity of the retrieved $\mathrm{CO}_{2}$ surface flux to uncertainties in $C$ varies with the first power of the boundary layer depth, and is inversely proportional to $t-t_{0}$ (see Eq. 23). This sensitivity is the inverse of the one shown in Fig. 5. $\partial\left\langle\left.\overline{w^{\prime} c^{\prime}}\right|_{s}\right\rangle / \partial C$ decreases during the morning until it reaches a minimum value because larger integration periods are considered and the boundary layer growth is small. In these conditions, the bulk $\mathrm{CO}_{2}$ mixing ratio only varies because of the surface flux. Then, between 08:00 and 10: UTC depending on the case, the boundary layer starts to grow faster and the

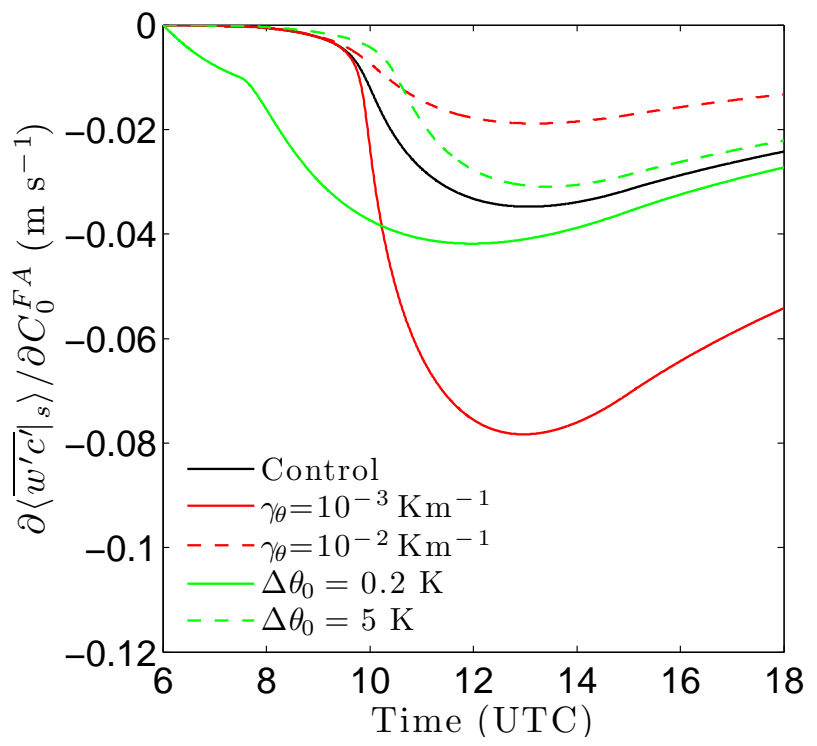

Fig. 8. Time evolution of the sensitivity of inferred surface flux of $\mathrm{CO}_{2}$ to initial value of the $\mathrm{CO}_{2}$ mixing ratio in the free atmosphere for the same boundary layers presented in Fig. 3.

sensitivity increases until approximately midday for the different studied cases because $C$ is not only controlled by the surface fluxes, but also by the entrainment fluxes. From midday, the growth of the boundary layer starts to decrease and the sensitivity decreases again until the end of the simulation. Opposite to what happened in Fig. 5, if the different cases are compared, from midday the smaller the boundary layer (less air entering in the boundary layer from the free atmosphere), the smaller the sensitivity.

Despite that $\partial\left\langle\left.\overline{w^{\prime} c^{\prime}}\right|_{s}\right\rangle / \partial h$ and $\partial\left\langle\left.\overline{w^{\prime} c^{\prime}}\right|_{s}\right\rangle / \partial h_{0}$ have the same dependence with the boundary layer depth and $t-t_{0}$, the evolution of these sensitivities is different. In the first case, it also depends on $C$. For this reason the evolution of $\partial\left\langle\left.\overline{w^{\prime} c^{\prime}}\right|_{s}\right\rangle / \partial h$ is more complicated, and due to its small relative value it will not be analyzed in detail. Regarding $\partial\left\langle\left.\overline{w^{\prime} c^{\prime}}\right|_{s}\right\rangle / \partial h_{0}$, by analyzing Eq. (21) it can be concluded that for the studied cases $\left(C_{0}^{\mathrm{FA}}-C_{0}\right) \gg \gamma_{c}\left(h-h_{0}\right)$. Consequently this sensitivity decreases with time approximately as $\left(t-t_{0}\right)^{-1}$.

The sensitivity of the retrieved $\mathrm{CO}_{2}$ surface flux to the initial $\mathrm{CO}_{2}$ mixing ratio in the free atmosphere, $C_{0}^{\mathrm{FA}}$, is also proportional to $h$ and inversely proportional to $t-t_{0}$. However, due to physical reasons this sensitivity should increase with the boundary layer growth. Mathematically, this fact is masked by the negative coefficient multiplying $h$ in Eq. (19), which makes that the evolution of $\partial\left\langle\left.\overline{w^{\prime} c^{\prime}}\right|_{s}\right\rangle / \partial C_{0}^{\mathrm{FA}}$ differs from the evolution of $\partial\left\langle\left.\overline{w^{\prime} c^{\prime}}\right|_{s}\right\rangle / \partial C$. Figure 8 shows the evolution of the sensitivity to the free atmospheric $\mathrm{CO}_{2}$ mixing ratio. At early morning, if the initial inversion strength is not too small, the boundary layer hardly grows until approximately 10:00 UTC (see Fig. 3a), and the absolute value of 


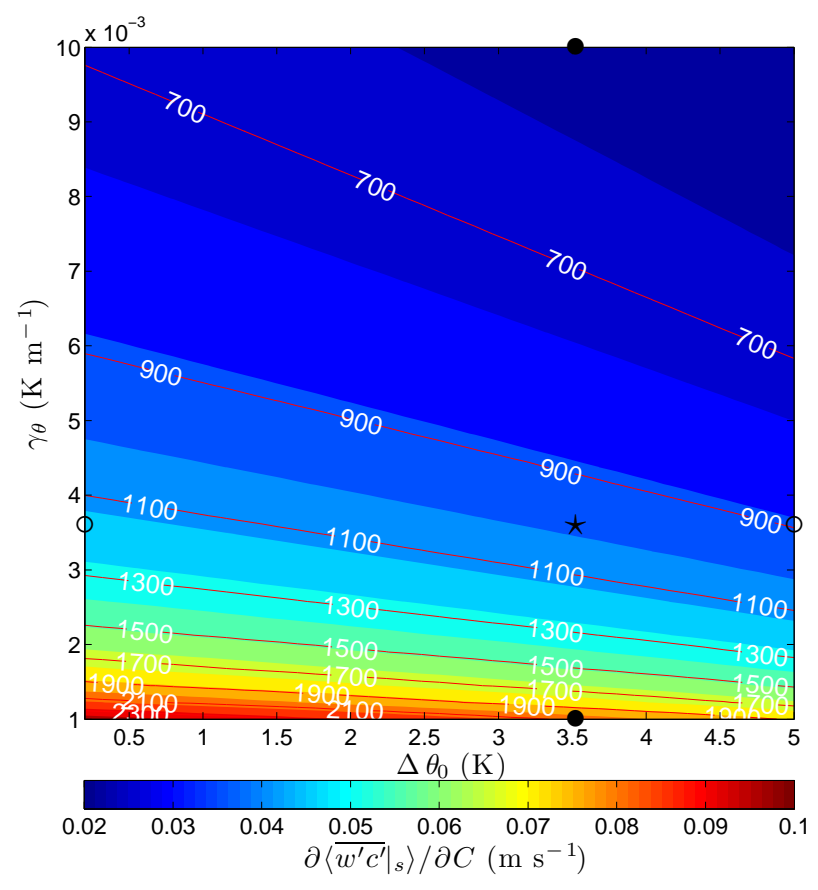

Fig. 9. Same as Fig. 6 for $\partial\left\langle\left.\overline{w^{\prime} c^{\prime}}\right|_{s}\right\rangle / \partial C$.

the sensitivity slightly increases. After 10:00 UTC, the rapid growth of the boundary layer (regime 2 in Fig. 2) yields to a faster increase with time of the absolute value of this sensitivity; that is, the conditions at the free atmosphere are important to infer the $\mathrm{CO}_{2}$ surface flux. Finally, from midday when the boundary layer grows very slowly (see Fig. 3a), the absolute value of the sensitivity decreases again. This result can appear counterintuitive. The reader can conclude that the influence of the errors made in the measurement of morning conditions in the free atmosphere should decrease during the day. However, as it was already mentioned in Sect. 2, $C_{0}^{\mathrm{FA}}$ is not only the morning value of the free atmospheric $\mathrm{CO}_{2}$ mixing ratio, but affects the whole free atmosphere, and consequently the whole boundary layer evolution. This fact can be understood if a case with $\gamma_{c}=0 \mathrm{ppm} \mathrm{m}^{-1}$ is considered. In this case, free atmospheric conditions only depends on $C_{0}^{\mathrm{FA}}$. Consequently, if the boundary layer growth yields to large entrainment rates, the free atmospheric conditions have a larger influence on the uncertainties in the determination of the $\mathrm{CO}_{2}$ surface flux, and the sensitivity to $C_{0}^{\mathrm{FA}}$ is larger.

It is important to study more in detail the influence of an inexact calculation or measurement of the evolution of the boundary layer depth on the inferred surface flux. If the control case $\left(\gamma_{\theta}=3.6 \times 10^{-3} \mathrm{~K} \mathrm{~m}^{-1}\right)$ and the case with $\gamma_{\theta}=10^{-3} \mathrm{~K} \mathrm{~m}^{-1}$ are compared (black and red solid lines in Fig. 3) several conclusions arise:
1. The difference in the boundary layer depth between these cases is around $1000 \mathrm{~m}$ at midday, around $100 \%$ difference (see Fig. 3a).

2. If the boundary layer depth of the control case is used as correct boundary layer depth for the case with $\gamma_{\theta}=10^{-3} \mathrm{~K} \mathrm{~m}^{-1}$ (wrong estimation/measurement of the boundary layer depth), an error on $C$ of approximately $0.8 \%$ is made at midday (compare red and black solid lines at Fig. 3b).

3. However, if the sensitivity of the inferred surface flux to uncertainties in the boundary layer depth is considered, $\partial\left\langle\left.\overline{w^{\prime} c^{\prime}}\right|_{s} /\right\rangle \partial h$ (not shown), the error made around 12:00 UTC is $\delta\left\langle\left.\overline{w^{\prime} c^{\prime}}\right|_{s}\right\rangle=\delta h \times \partial\left\langle\left.\overline{w^{\prime} c^{\prime}}\right|_{s} /\right\rangle \partial h \approx 1000 \times 2$ $10^{-4}=0.2 \mathrm{ppm} \mathrm{m} \mathrm{s}^{-1}$; twice the maximum value of the observed flux at noon. The same analysis can be made, with similar results, for the other variables. That is, although errors on the CBL characteristics may have small influence on the general evolution of $C$, they produce large errors when the inversion modeling is used to infer the surface flux because in many cases carbon dioxide budget can be dominated by entrainment effects. This result was already pointed out by Culf et al. (1997) but without studying the analytical form of the sensitivities.

By using the sensitivities of the $\mathrm{CO}_{2}$ mixing ratio and of the inferred surface flux (see Figs. 4 and 7) and Eq. (13), we extend the analysis for the control case to the contribution of all the variables to the error of the $\mathrm{CO}_{2}$ mixing ratio and of the inferred flux by considering hypothetical constant errors of the different variables, (see the first column of Table 2). We find that the contribution of some variables to the error on $C$ can be as large as $16 \mathrm{ppm}$ during the early morning, being the largest the contributions of $h$ and $h_{0}$ (not shown). From noon, when the boundary layer is fully developed the contribution of each error to the $\mathrm{CO}_{2}$ mixing ratio error is smaller than $2 \mathrm{ppm}$. Table 2 also shows the absolute and relative contributions of the error of each variable to the total error of $C$ at 14:00 UTC. The contributions of the errors in $h_{0}$, and in the free atmospheric conditions $\left(\gamma_{c}\right.$ and $\left.C_{0}^{\mathrm{FA}}\right)$ are the largest ones. This emphasizes the fact that in reality the errors in all the variables can be significant even if their relative sensitivity is small, and vice versa. To illustrate this, we analyze the contribution of error in $C_{0}$ to uncertainties in $C$ during the afternoon. As shown in Fig. 4, $C_{0}$ is one of the most important variables influencing $C$ evolution. $C_{0}$ observations can be quite accurately measured whereas models results might have large errors due to the complexity in modeling the previous stable boundary layer. Therefore, the modeled $C_{0}$ can be under or overestimated with respect the real value. As a result, and despite the sensitivity of $C$ to $C_{0}$ is the same (see expression 6), the observation and model methods produce different contributions to the error on the $\mathrm{CO}_{2}$ mixing ratio during the afternoon. 
Table 2. Absolute and relative contributions of the error on each variable to the total error of $C$ or $\left\langle\left.\overline{w^{\prime} c^{\prime}}\right|_{s}\right\rangle$ at 14:00 UTC assuming hypothetical constant errors of the different analyzed variables. To calculate the values at the third and fourth columns expression (13) is used with the corresponding value of the sensitivity at 14:00 UTC for the $\mathrm{CO}_{2}$ mixing ratio and the inferred surface flux, respectively.

\begin{tabular}{cccc}
\hline Variable & Hypothetical error & $\begin{array}{c}\text { Contribution to the total error of } C \\
\text { ppm }(\%)\end{array}$ & $\begin{array}{c}\left.\text { Contribution to the total error of }\left.\overline{\left\langle w^{\prime} c^{\prime}\right.}\right|_{s}\right\rangle \\
\mathrm{mg} \mathrm{m}^{-2} \mathrm{~s}^{-1}(\%)\end{array}$ \\
\hline$C_{0}$ & $1 \mathrm{ppm}$ & $0.109(2.27)$ & $0.0078(2.02)$ \\
$C_{0}^{\mathrm{FA}}$ & $1 \mathrm{ppm}$ & $0.890(18.6)$ & $0.063(16.6)$ \\
$C$ & $1 \mathrm{ppm}$ & - & $0.071(18.5)$ \\
$\gamma_{c}$ & $310^{-3} \mathrm{ppm} \mathrm{m}{ }^{-1}$ & $1.304(27.2)$ & $0.091(23.9)$ \\
$h_{0}$ & $50 \mathrm{~m}$ & $1.957(40.8)$ & $0.138(36.1)$ \\
$h$ & $50 \mathrm{~m}$ & $0.273(5.69)$ & $0.011(2.88)$ \\
$\left\langle\left.\overline{w^{\prime} c^{\prime}}\right|_{s}\right\rangle$ & $0.0186 \mathrm{mg} \mathrm{m}^{-2} \mathrm{~s}^{-1}$ & $0.262(5.44)$ & - \\
\hline
\end{tabular}

Regarding the error in the inferred $\mathrm{CO}_{2}$ surface flux after noon, the main contributors to $\delta\left\langle\left.\overline{w^{\prime} c^{\prime}}\right|_{s}\right\rangle$ are $h_{0}, \gamma_{c}, C$ and $C_{0}^{\mathrm{FA}}$ (see Table 2), that can have values as large as $0.09 \mathrm{mg} \mathrm{m}^{-2} \mathrm{~s}^{-1}$. Note that this value corresponds to half of the maximum measured $\mathrm{CO}_{2}$ surface flux during the day. The errors during the whole morning are even larger. During the afternoon, when the boundary layer growth is minimal, errors of $h$ and $C_{0}$ contribute much less to the error of the inferred $\mathrm{CO}_{2}$ surface flux. This analysis stresses the importance of morning and free atmospheric $\mathrm{CO}_{2}$ conditions are important to estimate the surface $\mathrm{CO}_{2}$ flux by using inverse techniques.

While better observing platforms and modeling strategies are pursued, the simple set of Eqs. (18)-(23) give an analytical framework on how to minimize the impact of errors even now. Careful selection of the time of day at which the surface flux estimate is made can help. For instance, Eq. (18) suggests that the impact of errors in the early morning $\mathrm{CO}_{2}$ concentration will be smaller if we had a very low nocturnal boundary layer $\left(h_{0}\right)$, and if we sample later in the day (large $\left.t-t_{0}\right)$. In contrast, Eq. (23) suggests that surface flux estimation due to errors in observed $\mathrm{CO}_{2}$ mixing ratios will also be smallest if we integrate over a longer time, but also while the CBL depth is low. This fact can be observed in Fig. 9, that shows the sensitivity of the inferred $\mathrm{CO}_{2}$ surface fluxes to the bulk $\mathrm{CO}_{2}$ mixing ratio $\left(\partial\left\langle\left.\overline{w^{\prime} c^{\prime}}\right|_{s}\right\rangle / \partial C\right.$, contours) and the boundary layer depth ( $h$, red solid lines) both averaged between 12:00 and 14:00 UTC for all the studied values of $\Delta \theta_{0}$ and $\gamma_{\theta}$. Take into account that the integration period starts at 06:00 UTC. The smallest sensitivities are found for large $\gamma_{\theta}$ and $\Delta \theta_{0}$, the conditions which produce the smallest boundary layer growth (see Fig. 3). By assessing each term in Eqs. (18)-(23) under given conditions one could make an informed decision on which time of day to use in the integration. Such an assessment could be made from the model output of a global or mesoscale model that includes $\mathrm{CO}_{2}$ transport, and then be used to inform an inverse estimate.
Taking into account that for $\partial\left\langle\left.\overline{w^{\prime} c^{\prime}}\right|_{s}\right\rangle / \partial C_{0}^{\mathrm{FA}}$ and $\partial\left\langle\left.\overline{w^{\prime} c^{\prime}}\right|_{S}\right\rangle \partial h_{0}$ between 12:00 and 14:00 UTC the larger the boundary layer depth the larger the absolute value of the sensitivity, Fig. 9 can be also used to qualitatively describe these sensitivities at this time of the day. The sensitivity of the inferred $\mathrm{CO}_{2}$ surface flux to uncertainties in $\gamma_{c}$ has also a positive dependence with the boundary layer depth but in a quadratic form (see Eq. 20).

The averaged sensitivity of the inferred $\mathrm{CO}_{2}$ surface flux to uncertainties in $h$ has a more complex behavior. Due to the dependence of the sensitivity on $C$ and $h$ (see Eq. 22), there is a minimum in the sensitivity averaged between 12:00 and 14:00 UTC that depends on the relation $C-\gamma_{c} h$ (not shown). For the values of $C_{0}^{\mathrm{FA}}, \gamma_{c}$ and $h_{0}$ considered here the minimum is at $\Delta \theta_{0}=0.2 \mathrm{~K}$ and $\gamma_{\theta}=0.0028 \mathrm{~K} \mathrm{~m}^{-1}$.

\section{Conclusions and outlook to inverse modeling}

Based on mixed-layer theory, we have derived analytical expressions to quantify the dependence of the key components of $\mathrm{CO}_{2}$ budget on boundary layer dynamics. Boundary layer depth is the main variable controlling the diurnal evolution of the $\mathrm{CO}_{2}$ mixing ratio. We have quantified the uncertainties in the calculations of the $\mathrm{CO}_{2}$ mixing ratio and inferred surface flux as a function of the boundary layer depth. We have further extended the study to boundary layer depth driven variables like the inversion strength and the stratification conditions in the free atmosphere.

The diurnal evolution of the carbon dioxide mixing ratio has been studied by using observations and mixed-layer theory during a convective day with low winds. The mixed layer model satisfactorily reproduces the observed diurnal evolution of the boundary layer depth, potential temperature and $\mathrm{CO}_{2}$ mixing ratio.

The normalization of the sensitivities has been used to study the relative importance of the boundary layer variables 
on the $\mathrm{CO}_{2}$ budget. Regarding the uncertainties in the calculation of the $\mathrm{CO}_{2}$ mixing ratio at midday, these are due $80 \%$ to the uncertainties in the morning $\mathrm{CO}_{2}$ mixing ratio in the free atmosphere and $15 \%$ in the mixed layer. The sensitivity to the other studied variables $\left(\gamma_{c}, h_{0}, h,\left.\overline{w^{\prime} c^{\prime}}\right|_{s}\right)$ is one order of magnitude lower. The inferred $\mathrm{CO}_{2}$ surface flux is mainly sensitive to the same variables, and to the actual value of the $\mathrm{CO}_{2}$ mixing ratio. Therefore, this study shows that reliable information about the $\mathrm{CO}_{2}$ mixing ratio not only near the surface but also in the free atmosphere is needed to reduce the error in the calculation of the inferred $\mathrm{CO}_{2}$ surface flux.

Regarding the temporal evolution of the sensitivities, it has been shown that most of the sensitivities of the $\mathrm{CO}_{2}$ mixing ratio and the inferred surface flux can be qualitatively described by the evolution of the $\mathrm{CO}_{2}$ bulk mixing ratio or of the boundary layer depth and the integration period. Only the sensitivity of the inferred $\mathrm{CO}_{2}$ surface flux to the $\mathrm{CO}_{2}$ gradient in the free atmosphere evolves with $h^{2}$, and the sensitivity of the inferred $\mathrm{CO}_{2}$ surface flux to the boundary layer depth has a dependence on $h$ but also on $C$. Its evolution from midday depends on the balance between the evolution of the bulk mixing ratio, $C$, and $\gamma_{c} h$ (see Eq. 22). In general, the different regimes (early morning, growth, and afternoon) of the boundary layer growth, that depends on the initial inversion strength and the evolution of the surface fluxes, combined with the integration period explain the evolution of all the studied sensitivities.

The studied day was well characterized and analyzed in previous research and because of its low advection rates, and high entrainment flux relative to the surface flux. This raises the question to what extent we can generalize our findings to other locations and times. One can assume that the ratio of entrainment to surface flux contribution to $\mathrm{CO}_{2}$ mixing ratios is important because with a high ratio, a small relative error in entrainment will lead to large changes in $\mathrm{CO}_{2}$ mixing ratios and subsequently to large relative surface flux estimation errors if the inverse method is applied. However, by looking at the Eqs. (18)-(23) it can be concluded that the absolute error in estimated surface flux does not depend explicitly on the entrainment or surface fluxes themselves. The equations that quantify the surface flux errors are therefore equally valid over all mixed-layer characteristics whether they represent croplands in summer or shrubs in winter, as long as the mixed-layer equations are applicable. This fact allow us to apply this study to other typical convective days with low advection regimes. In a future work, where advection will be considered, other days with higher $\mathrm{CO}_{2}$ advection regimes will be analyzed.

When using inverse long-range tracer transport models, $\mathrm{CO}_{2}$ mixing ratios and estimations of the inferred $\mathrm{CO}_{2}$ surface fluxes are usually averaged over monthly, seasonal or annual time scales. One major drawbacks of the analysis presented here is that it only accounts for daytime evolution of the boundary layer. Mixed layer models cannot describe stable boundary layers occurring during the night and therefore,

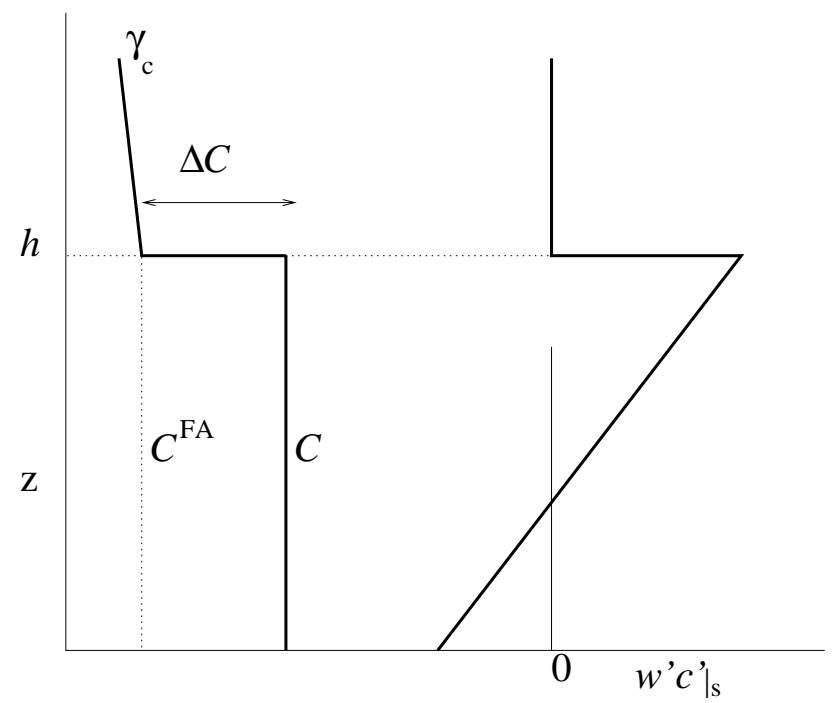

Fig. 10. Schematic representations of the vertical profiles of (left) the $\mathrm{CO}_{2}$ mixing ratio and (right) the $\mathrm{CO}_{2}$ flux of a convective boundary layer as the one studied here in a zeroth-order jump mixed layer model.

the mixed layer equations cannot be just integrated over long time periods. The importance of different processes on the $\mathrm{CO}_{2}$ evolution is expected to significantly change at longer time scales. Williams et al. (2011) showed that on long time scales (one to three months) the storage and entrainment terms of the $\mathrm{CO}_{2}$ budget become increasingly insignificant compared to the surface flux and advection. Due to this reason entrainment or storage are sometimes neglected when longer time scales are of interest (Bakwin et al., 2004; Helliker et al., 2008). This approximation is commonly referred as an equilibrium approximation. On shorter time scales a non-equilibrium approximation is sometimes used which neglects the advection terms (Yi et al., 2004). Short term and long term behavior are thus quite opposite which emphasizes that it is not appropriate to simply apply the diurnal analysis to longer time scales. The analysis presented here can however be used to make better estimations about the applicability of nonequilibrium approximation during the day that is investigated.

\section{Appendix A}

\section{Derivation of the classical mixed layer equation}

From Eq. (1), an equivalent formulation of the zeroth-order classical mixed-layer theory (Tennekes, 1973; Tennekes and Driedonks, 1981) can be derived. The derivation of this equation reads:

$h \frac{\partial C}{\partial t}+C \frac{\partial h}{\partial t}=\left.\overline{w^{\prime} c^{\prime}}\right|_{s}+C^{\mathrm{FA}} \frac{\partial h}{\partial t}$, 
that can be written as:

$$
\frac{\partial C}{\partial t}=\frac{1}{h}\left[\left.\overline{w^{\prime} c^{\prime}}\right|_{s}+\Delta C \frac{\partial h}{\partial t}\right],
$$

where $\Delta C=C^{\mathrm{FA}}-C$. This is a more widely used form in mixed-layer theory. Typical diurnal vertical profiles of the $\mathrm{CO}_{2}$ mixing ratio (left) and vertical flux (right) are sketched in Fig. 10. In this figure, the $\mathrm{CO}_{2}$ mixing ratio (left) is constant in the mixed layer and larger than $C^{\mathrm{FA}}$ just above the inversion. The $\mathrm{CO}_{2}$ mixing ratio in the FA usually decreases or is constant with height $\left(\gamma_{c} \lesssim 0\right)$. On the right, the normal conditions during the day are represented, negative surface and positive entrainment $\mathrm{CO}_{2}$ fluxes, both reducing the $\mathrm{CO}_{2}$ mixing ratio in the boundary layer.

Both approaches, by using the integral equation and the more widely form of the mixed-layer theory, require to solve an equation for $h$ that depends on the surface heat fluxes and the dynamic factors of the boundary layer. That is on the heat/moisture budget (van Heerwaarden et al., 2010). However, the main difference with the classical mixed-layer theory is that in this case the only variables needed to calculate the bulk $\mathrm{CO}_{2}$ mixing ratio are the $\mathrm{CO}_{2}$ surface flux and the integration boundary. The latter is driven by the surface heat fluxes in a mixed-layer model. Moreover, as long as the free atmosphere is an infinite reservoir, the possible mixing within the mixing-layer is irrelevant, because it would occur within the integral limits. That is, in addition of the surface flux the only variable to take into account is the growth of the boundary layer because from this, the amount of $\mathrm{CO}_{2}$ coming from the free atmosphere and introduced in the mixed layer can be calculated. In our research this boundary layer depth is calculated by using mixed-layer theory (Tennekes and Driedonks, 1981; Pino et al., 2006).

Acknowledgements. The work has been performed under the HPC-EUROPA2 project (project number: 228398) with the support of the European Commission-Capacities Area-Research Infrastructures, Spanish MICINN project CGL2009-08609, and INTERREG EU project FLUXPYR EFA 34/08. We would also like to acknowledge Fred Bosveld of the Royal Netherlands Meteorological Institute (KNMI) and Alex Vermeulen of the Energy Research Center of The Netherlands (ECN) for the observational data used, and Jukka-Pekka Kaikkonen (Aalto University) for his very helpful comments during the revision of the manuscript.

Edited by: T. Karl

\section{References}

Aubinet, M., Feigenwinter, C., Heinesch, B., Bernhofer, C., Canepa, E., Lindroth, A., Montagnani, L., Rebmann, C., Sedlak, P., and Van Gorsel, E.: Direct advection measurements do not help to solve the night-time $\mathrm{CO}_{2}$ closure problem: Evidence from three different forests, Agr. Forest Meteorol., 150, 655-664, 2010.
Bakwin, P. S., Davis, K. J. , Yi, C., Wofsy, S. C., Munger, J. W., Haszpra, L., and Barcza, Z.: Regional carbon dioxide fluxes from mixing ratio data, Tellus $B, 56$, 301-311, 2004.

Baldocchi, D., Falge, E., Gu, L., Olson, R., Hollinger, D., Running, S., Anthoni, P., Bernhofer, Ch., Davis, K., Evans, R., Fuentes, J., Goldstein, A., Katul, G., Law, B., Lee, X., Malhi, Y., Meyers, T., Munger, W., Oechel, W., Paw U, K. T., Pilegaard, K., Schmid, H. P., Valentini, R., Verma, S., Vesala, T., Wilson, K., and Wofsyn, S.: FLUXNET: A New Tool to Study the Temporal and Spatial Variability of Ecosystem-Scale Carbon Dioxide, Water Vapor, and Energy Flux Densities, Bull. Amer. Soc., 82, 2415-2434, 2001.

Beljaars, A. C. M. and Bosveld, F. C.: Cabauw data for the validation of land surface parameterization schemes, J. Clim., 10, 1172-1193, 1997.

Bosveld, F. C., van Meijgaard, E., Moors, E., and Werner, C.: Interpretation of flux observations along the Cabauw 200 m meteorological tower, in 16th Symp. Boundary Layers and Turbulence, Portland (USA), 9-13 August, J6.18, 2004.

Bousquet, P., Ciais, P., Peylin, P., Ramonet, M., and Monfray, P.: Inverse modeling of annual atmospheric $\mathrm{CO}_{2}$ sources and sinks 2. Sensitivity study, J. Geophys. Res., 104, 26179-26193, doi:10.1029/1999JD900342, 1999.

Casso-Torralba, P., Vilà-Guerau de Arellano, J.,Bosveld, F., Soler, M. R., Vermeulen, A., Werner, C., and Moors, E.: Diurnal and vertical variability of the sensible heat and carbon dioxide budgets in the atmospheric surface layer, J. Geophys. Res., 113, D12119, doi:10.1029/2007JD009583, 2008.

Culf A. D., Fisch G., Malhi, G, Y., and Nobre, C. A.: The influence of the atmospheric boundary layer on carbon dioxide concentrations over a tropical forest, Agr. Forest Meteorol., 85, 149-158, 1997.

Dang, X., Lai, C.-T., Hollinger, D. Y., Schauer, A. J., Xiao, J., Munger, J. W., Owensby, C., and Ehleringer, J. R.: Combining tower mixing ratio and community model data to estimate regional-scale net ecosystem carbon exchange by boundary layer inversion over four flux towers in the United States, J. Geophys Res., 116, G03036, doi:10.1029/2010JG001554, 2011.

Denning, A. S., Fung, I. Y., and Randall, D.: Latitudinal gradient of atmospheric $\mathrm{CO}_{2}$ due to seasonal exchange with land biota, Nature, 376, 240-243, 1995.

Denning A. S., Collatz, G. J., Zhang, C. G., Randall, D. A., Berry, J. A., Sellers, P. J., Colello, G. D., and Dazlich, D. A.: Simulations of terrestrial carbon metabolism and atmospheric $\mathrm{CO}_{2}$ in a general circulation model, 1 . Surface carbon fluxes, Tellus B, 48, 521-542, 1996.

Desjardins, R. L., Hart, R. L., MacPherson, J. I., Schuepp, P. H., and Verma, S. B.: Aircraft- and Tower-Based Fluxes of Carbon Dioxide, Latent, and Sensible Heat, J. Geophys. Res., 7, 18477 18485, 1992.

Desjardins, R. L., MacPherson, J. I., Neumann, H., Den Hartog, G., and Schuepp, P. H.: Flux estimates of latent and sensible heat, carbon dioxide, and ozone using an aircraft-tower combination, Atmos. Env., 29, 3147-3158, 1995.

Eugster, W. and Siegrist, F.: The influence of nocturnal $\mathrm{CO}_{2}$ advection on $\mathrm{CO}_{2}$ flux measurements, Basic Appl. Ecol., 1, 177-188, 2000.

Font, A., Morguí, J.-A., Curcoll, R., Pouchet, I., Casals, I., and Rodó, X.: Daily carbon $\mathrm{CO}_{2}$ in the West Ebre (Ebro) watershed 
from aircraft profiling on late June 2007, Tellus B, 62, 427-440, 2010.

Gerbig, C., Körner, S., and Lin, J. C.: Vertical mixing in atmospheric tracer transport models: error characterization and propagation, Atmos. Chem. Phys., 8, 591-602, doi:10.5194/acp-8591-2008, 2008.

Göckede, M, Michalak, A. M., Vickers, D., and Turner, D. P.: Atmospheric inverse modeling to constrain regional-scale $\mathrm{CO}_{2}$ budgets at high spatial and temporal resolution, J. Geophys. Res., 115, D15113, doi:10.1029/2009JD012257, 2010.

Górska, M., Vil-Guerau de Arellano, J., LeMone M. A., and van Heerwaarden, C. C.: Mean and Flux Horizontal variability of virtual potential temperature, moisture, and carbon dioxide: Aircraft observations and LES study, Mon. Weather Rev., 136, 44354451, doi:10.1175/2008MWR2230.1, 2008.

Helliker, B. R., Berry, J. A., Betts, A. K., Bakwin, P. S., Davis, K. J., Denning, A. S., Ehleringer, J. R., Miller, J. B., Butler, M P., Ricciuto, D. M.: Estimates of net $\mathrm{CO} 2$ flux by application of equilibrium boundary layer concepts to $\mathrm{CO} 2$ and water vapor measurements from a tall tower, J. Geophys. Res., 109, D20106, doi:10.1029/2004JD004532, 2004.

Huang, J., Lee, X, and Patton, E. G.: Entrainment and budgets of heat, water vapor, and carbon dioxide in a convective boundary layer driven by time-varying forcing, J. Geophys. Res., 116, D06308, doi:10.1029/2010JD014938, 2011.

Jacobs C. M. J. and De Bruin, H. A. R.: The sensitivity of regional transpiration to land-surface characteristics: Significance of feedback, J. Clim., 5, 683-698, 1992.

Keppel-Aleks, G., Wennberg, P. O., Washenfelder, R. A., Wunch, D., Schneider, T., Toon, G. C., Andres, R. J., Blavier, J.-F., Connor, B., Davis, K. J., Desai, A. R., Messerschmidt, J., Notholt, J., Roehl, C. M., Sherlock, V., Stephens, B. B., Vay, S. A., and Wofsy, S. C.: The imprint of surface fluxes and transport on variations in total column carbon dioxide, Biogeosciences, 9, 875891, doi:10.5194/bg-9-875-2012, 2012.

Kim, J. and Verma, S. B.: Carbon dioxide exchange in a temperate grassland ecosystem, Bound.-Lay. Meteorol., 52, 135-149, 1990.

Lemone, M., Grossman, R., McMillen, R., Liou, K., Ou, S., Mckeen, S., Angevine, W., Ikeda, K., and Chen, F.: Cases-97: Latemorning warming and moistening of the convective boundary layer over the Walnut River watershed, Bound.-Lay. Meteorol., 104, 1-52, 2002.

Lilly, D. K.: Models of cloud-topped mixed layer under a strong inversion, Quart. J. Roy. Meteor. Soc., 94, 292-309, 1968.

Lloyd, J. and Taylor, J. A.: On the temperature dependence of soil respiration, Functional Ecol., 8, 315-323, 1994.

McGrath-Spangler, E. and Denning S.: Impact of entrainment from overshooting thermals on land-atmosphere interactions during summer 1999, Tellus B, 62, 441-454, 2010.

Pino, D. and Vilà-Guerau de Arellano, J.: Role of the boundarylayer processes in understanding the $\mathrm{CO}_{2}$ budget, 19th Symposium on Boundary Layers and Turbulence, Keystone (USA), 2-6 August, J9.1, 2010.

Pino, D., Vilà-Guerau de Arellano, J., and Kim, S. -W.: Representing sheared convective boundary layer by zeroth- and first-orderjump mixed layer models: Large-eddy simulation verification, J. Appl. Meteor. Clim., 45, 1224-1243, 2006.

Stephens, B. B., Gurney, K. R., Tans, P. P., Sweeney, C., Peters, W.,
Bruhwiler, L., Ciais, P., Ramonet, M., Bousquet, P., Nakazawa, T., Aoki, S., Machida, T., Inoue, G., Vinnichenko, N., Lloyd, J., Jordan, A., Heimann, M., Shibistova, O., Langenfelds, R. L., Steele, L. P., Francey, R. J., and Denning, A. S.: Weak Northern and Strong Tropical Land Carbon Uptake from Vertical Profiles of Atmospheric $\mathrm{CO}_{2}$, Science, 316, 1732-1735, 2007.

Stull, R. B.: An Introduction to Boundary Layer Meteorology, Kluwer Academic, Dordrecht, The Netherlands, 670 pp., 1988.

Sun, J., Burns, S. P., Delany, A. C., Oncley, S. P., Turnipseed, A. A. Stephens, B. B., Lenschow, D. H., LeMone, M. A., Monson, R. K., Anderson, D. E.: $\mathrm{CO}_{2}$ transport over complex terrain, Agr. Forest Meteorol., 145, 1-21, 2007.

Tennekes, H.: A model for the dynamics of the inversion above a convective boundary layer, J. Atmos. Sci., 30, 558-567, 1973.

Tennekes, H. and Driedonks, A. G. M.: Basic entrainment equations for the atmospheric boundary layer, Bound.-Lay. Meteorol., 20, 515-531, 1981.

Ter Maat, H. W., Hutjes, R. W. A., Miglietta, F., Gioli, B., Bosveld, F. C., Vermeulen, A. T., and Fritsch, H.: Simulating carbon exchange using a regional atmospheric model coupled to an advanced land-surface model, Biogeosciences, 7, 2397-2417, 2010 ,

http://www.biogeosciences.net/7/2397/2010/.

van Heerwaarden, C. C., Vilà-Guerau de Arellano, J., Gounou, A., Couvreux, F., and Guichard, F.: Understanding the daily cycle of evapotranspiration: a new method to quantify the influence of forcings and feedbacks, J. Hydrometeorol., 11, 1405-1422, doi:10.1175/2010JHM1272.1, 2010.

Vermeulen, A. T., Hensen, A., Popa, M. E., van den Bulk, W. C. M., and Jongejan, P. A. C.: Greenhouse gas observations from Cabauw Tall Tower (19922010), Atmos. Meas. Tech., 4, 617644, doi:10.5194/amt-4-617-2011, 2011.

Vilà-Guerau de Arellano, J., Gioli, B., Miglietta, F., Jonker, H., Baltink, H., Hutjes, R., and Holtslag, A.: Entrainment process of carbon dioxide in the atmospheric boundary layer, J. Geophys. Res., 109, D18110, doi:10.1029/2004JD004725, 2004.

Vilà-Guerau de Arellano, J., van den Dries, K., and Pino, D.: On inferring isoprene emission surface flux from atmospheric boundary layer concentration measurements, Atmos. Chem. Phys., 9, 3629-3640, doi:10.5194/acp-9-3629-2009, 2009

Werner, C., Bosveld, F., Vermeulen, A., and Moors, E.: The role of advection on $\mathrm{CO}_{2}$ flux measurements at the Cabauw tall tower, Netherlands, in 27th Conf. on Agricultural and Forest Meteorology, San Diego (USA), 22-26 May, JP5.3, 2006.

Williams, I. N., Riley, W. J., Torn, M. S., Berry, J. A., and Biraud, S. C.: Using boundary layer equilibrium to reduce uncertainties in transport models and $\mathrm{CO}_{2}$ flux inversions, Atmos. Chem. Phys., 11, 9631-9641, doi:10.5194/acp-11-9631-2011, 2011.

Wofsy, S. C., Harriss, R. C., and Kaplan, W. A.: Carbon dioxide in the atmosphere over the Amazon basin, J. Geophys. Res., 93, 1377-1387, 1988.

Yang, Z., Washenfelder, R., Keppel-Aleks, G., Krakauer, N. Y., Randerson, J. T., Tans, P. P., Sweeney, C., and Wennberg, P. O.: New constraints on Northern Hemisphere growing season net flux, Geophys. Res. Lett., 34, L12807, doi:10.1029/2007GL029742, 2007.

Yi, C., Davis, K. J., Bakwin, P. S., Berger, B. W., and Marr, L. C.: Influence of advection on measurements of the net ecosystematmosphere exchange of $\mathrm{CO}_{2}$ from a very tall tower, J. Geophys 
Res., 105, 9991-9999, 2000.

Yi, C., Davis, K. J., Bakwin, P. S., Denning, A. S., Zhang, N., Desai, A., Lin, J. C., and Gerbig, C.: Observed covariance between ecosystem carbon exchange and atmospheric boundary layer dynamics at a site in northern Wisconsin, J. Geophys. Res., 109, D08302, doi:10.1029/2003JD004164, 2004.
Yi, C., Anderson, D. E., Turnipseed, A. A., Burns, S. P., Sparks, J. P., Stannard, D. I., and Monso, R. K.: The contribution of advective fluxes to net ecosystem exchange in a high-elevation, subalpine forest, Ecol. Appl., 18, 1379-1390, 2008. 